\title{
A MODEL FOR THE MIGRATION OF THE FISSION PRODUCTS ALONG THE COOLANT CHANNELS OF A HIGH TEMPERATURE GAS COOLED REACTOR \\ FOLLOWING A HYPOTHETICAL ACCIDENT OF COMPLETE LOSS OF COOLING
}

J. M. Dickey

May 1978

INFORMAL REPORT

HTGR Safety Division Department of Nuclear Energy Brookhaven National Laboratory Associated Universities, Inc. Upton, New York, 11973
This report was prepared as an acter. sponsored by the United States an account of work United States nor the United States Deperther the Energy, nor any of their employees. Deparment of confractors, subcontractors, or their, nor any of theis any warranty, express or implied, or assoyees, makes hability or responsibility for the accursumes any legal or usefulness of any information, appey, completeness process disclosed, or represents, apparatus, product or infringe privately owned rights. 


\section{DISCLAIMER}

This report was prepared as an account of work sponsored by an agency of the United States Government. Neither the United States Government nor any agency Thereof, nor any of their employees, makes any warranty, express or implied, or assumes any legal liability or responsibility for the accuracy, completeness, or usefulness of any information, apparatus, product, or process disclosed, or represents that its use would not infringe privately owned rights. Reference herein to any specific commercial product, process, or service by trade name, trademark, manufacturer, or otherwise does not necessarily constitute or imply its endorsement, recommendation, or favoring by the United States Government or any agency thereof. The views and opinions of authors expressed herein do not necessarily state or reflect those of the United States Government or any agency thereof. 


\section{DISCLAIMER}

Portions of this document may be illegible in electronic image products. Images are produced from the best available original document. 

Abstract

List of Tables

vi

List of Figures

vii

1

Introduction

1

2 Proposed Core Design of a High Temperature Gas Reactor

3

Hypothetical Accident Scenario and Data Used for the

Calculations

Inventory of Fission Products in the Core 4

Temperature History ․ 5

Coolant Pressure 5

Coolant Flow Rate 5

Diffusion Coefficients in Graphite 6

Vapor Pressure $\quad 6$

4 Theory of Evaporation and Deposition in the Coolant Channels '8 and Code EVAP

$\begin{array}{ll}\text { Code EVAP } & 10\end{array}$

Concentration of the Fission Products at the Surface 11

of a Channel

Radioactive Decay of the Fission Products 13

5 Results of the Calculations Using EVAP 13

Results for Different Elements 13

Redistribution of the Fission Products Among the Segments 14

of the Coolant Channels

Effect of Different Temperature Sequences 
Effect of the Flow Rate

Effect of Pressure

Effect of Vapor Pressure Calculation

Effect of Diffusion

Reflector Approximation

References 


\section{ABSTRACT}

Under the assumption that a nonmechanistic accident induces a condition such that it is not possible to cool the core of a high temperature gas cooled reactor, the temperature of the core will gradually rise due to decay heat. There are several barriers to the release of fission products to the environment: the fuel particle coatings, the graphite moderator, the prestressed concrete reactor vessel and the containment.

A code, EVAP, has been written to calculate one stage in the release, the migration of the fission products along the coolant channels. The calculations, using the code, are reported for 10 fission products, based on typical conditions which might occur in the course of the hypothetical accident. The sensitivity of the results to several important parameters is examined. 


\section{LIST OF TABLES}

$\underline{\text { Page }}$

Table 3.1 Data for the proposed design of a 3000 MWt HTGR and

typical values of the parameters used in the calcula-

tions. The data is taken from relevant publications by

General Atomic.

Table $3.2 \quad$ Power factors.

Table 3.3 Diffusion coefficients for elements in graphite.

Table $3.4 \quad$ Vapor pressure constants.

Table 4.1 Approximate time, in hours, each element would take

to diffuse from the fuel rods and to establish an almost uniform concentration throughout the graphite matrix. 


\section{LIST OF FIGURES}

Page

Figure 2.1 Proposed design for a 3000 MWt HTGR core. ${ }^{2}$

Figure 2.2 Mathematical model of core used in EVAP. 2

Figure 3.1 Variation of the predicted temperature ${ }^{1}$ along a coolant channel in the central region of the core. The temperature is taken to be uniform within each segment of the channel. The full line refers to a time of 21 hours and the dashed line to a time of 29 hours after the hypothetical accident.

Figure 3.2 Variation of the predicted temperature ${ }^{1}$ with time for the segments in the central region of the core. Segment 1 is the lowest segment.

Figure 3.3 Evolution of the average and maximum predicted temperatures ${ }^{1}$ of the core.

Figure 4.1 Experimental data and theoretical predictions for mass transfer in a circular channel. 9

Figure 4.2 Model of the coolant channels and graphite web used in EVAP.

Figure 4.3 Approximate time, in hours, for attainment of an approximately even concentration within the graphite matrix.

Figure 5.1 Fraction of the elements indicated which escapes into the upper plenum.

Figure 5.2 Fraction of the elements indicated which migrates into the top reflector.

Figure 5.3 Fraction of the elements indicated which escapes into the upper plenum from the central region of the core. 
Figure 5.4 Fraction of the elements indicated which migrates into the top reflector from the central region of the core.

Figure 5.5 The migration of Eu along the coolant channels. Curves 1-8 refer to the segments of the active core starting at the bottom; R1 and $R 2$ refer to the top reflector and $P$ refers to the upper plenum.

Figure 5.6 The migration of $\mathrm{Pr}$ along the coolant channels. Curves 1-8 refer to the segments of the active core starting at the bottom; R1 and R2 refer to the top reflector and $P$ refers to the upper plenum.

Figure 5.7 The migration of Eu along a coolant channel in the central region of the core. Curves $1-8$ refer to the segments of the active core starting at the bottom; $\mathrm{R} 1$ and $\mathrm{R} 2$ refer to the top reflector and $P$ refers to the upper plenum.

Figure 5.8 The migration of $\operatorname{Pr}$ along a coolant channel in the central region of the core. Curves $1-8$ refer to the segments of the active core starting at the bottom; RI and $R 2$ refer to the top reflector and $P$ refers to the upper plenum.

Figure 5.9 The amount of Eu which has escaped from each region of the core into the upper plenum. The core is divided into 14 radial regions; region 1 is the central region.

Figure 5.10 The effect of the flow rate of the helium on the amount of Eu released from the central region of the core. The basic flow rate of $5.67 \times 10^{3}$ moles/hour is multiplied by the factors shown.

Figure 5.11 The effect of the flow rate of the helium on the migration of $\operatorname{Pr}$ in the central region of the core. The basic flow rate of $5.67 \times 10^{3}$ moles/hour is multiplied by the 
factors shown.

Figure 5.12 The release curves for Eu, Sm and Pm for a flow rate of $5.67 \times 10^{4}$ moles/hour. The curves are for the central region of the core.

Figure 5.13 The amount of Eu released from the central region of the core if the ambient pressure is $1 \mathrm{~atm}$. or 2 atm.

Figure 5.14 The full curve is the fraction of Eu which escapes into the upper plenum from the central region of the core if the vapor pressure calculated is that of Eu. The dashed curve is the fraction of the Eu which migrates into the top reflector from the central region of the core if the vapor pressure calculated is that of $\mathrm{EuC}_{2}$.

Figure 5.15 Fraction of Eu which escapes into the upper plenum from the central region of the core assuming that the concentration corresponding to a monolayer coverage is the figure quoted in Table 3.4 and corresponding to a half of this value.

Figure 5.16 Comparison of the results of the reflector approximation, dashed curve, with the results for each channel divided into 10 segments, full curve. The curves show the fraction, of the elements indicated, which escapes into the upper plenum from the central region of the core. 


\section{Introduction}

The assumption that a nonmechanistic condition induces a loss of the capability to cool the core of a high temperature gas cooled reactor (HTGR) leads to a hypothetical accident, which could have, potentially, serious consequences. Following such a hypothetical accident, it is conceivable that a large fraction of the fission products in the core could be released to the environment. A nonmechanistic example of such a hypothetical scenario, is a pipe rupture, which causes loss of the coolant, followed by a failure of the primary coolant pumps and emergency core cooling system. Such a hypothetical failure would result in an immediate reactor trip. The subsequent decay of the fission products would generate a considerable amount of heat. In the absence of forced circulation, it is predicted that this heat cannot be removed quickly by conduction and radiation. Therefore, the temperature of the core would not remain within the range of normal operating conditions, but would gradually rise to the sublimation temperature of graphite. To indicate the time scale predicted, ${ }^{1}$ after about 10 hours, the maximum temperature anywhere in the core would be about $4800^{\circ} \mathrm{F}$ and after about 50 hours, about one third of the core would be at $6500^{\circ} \mathrm{F}$.

There will be no immediate release of the fission products, as the fuel particle coatings are almost impervious for temperatures a few hundred degrees above operating temperatures. After escaping from the fuel particles, one may conservatively assume that the most volatile elements, the rare gases and the halogens, escape directly into the primary coolant circuit. The release of the nonvolatile elements, on the other hand, is retarded by the graphite moderator. These elements must diffuse across the graphite web to the coolant channel surface and evaporate from this surface. Initially, this process will 
merely result in a redistribution of the fission products, as the mobile elements will evaporate from the hotter regions of the core and redeposit on the cooler regions. As the cooler parts of the core heat up and the reflector also heats up, eventually some of the atoms may escape from the core into the upper plenum. If the integrity of the graphite remains intact then diffusion and evaporation are the only pathways for release, and refractory elements, such as $\mathrm{Nb}$ are predicted to remain indefinitely in the core.

Schwartz et $a 1^{2}$ have written a code, SORS, which calculates the release of fission products from the core during a transient temperature excursion. SORS calculates the release from the fuel particles, and the diffusion through the graphite and the evaporation. The approach and mathematical technique used in SORS have recently been reviewed. 3 This report discusses one aspect of the problem, the evaporation and migration of the fission products in the coolant channels. A code, EVAP, has been written to calculate the redistribution of an impurity along a channel through which the coolant is flowing slowly. The first version of EVAP assumes a constant source term. In later versions, the code may be modified to allow the source term to vary with time, in order to take into account the earlier stages in the migration of the fission products in different parts of the core.

Section 2 describes briefly the proposed design for the core of an HTGR and the model of the core used in the code. In section 3 we describe the hypothetical accident scenario and the predicted magnitude of the relevant parameters during the course of the hypothetical accident. In Section 4 we discuss the theory of mass transfer in a channel with a slowly flowing coolant stream, and the approximation for diffusion. Section 5 presents the results of calculations made using the code EVAP. The description and calculation are based on data 
for a previously proposed design for a 3000 MWt HTGR from relevant publications by General Atomic, unless otherwise stated.

\section{Proposed Core Design of a High Temperature Gas Reactor}

The fuel is contained in spherical fuel particles, which have a ceramic coating. At normal operating temperature, the fuel particle coatings are almost impermeable to the fission products. The rate at which fission products can leak out of the particles, increases as the temperature is raised. At a sufficiently high temperature, the coatings fail and the fission products can escape. Most of the fission products escape in a narrow range of temperature around $2000^{\circ} \mathrm{C}^{3}$ The fuel particles are mixed with carbonized pitch and graphite flour and the mixture is formed into cylindrical fuel rods which are placed in holes drilled in the fuel elements. The fuel elements are hexagonal blocks of graphite. Each standard fuel element contains 132 fuel rods and 72 coolant channels. Eight fuel elements are stacked in a vertical column and similar blocks of graphite are placed at the top and bottom to act as reflectors. The coolant channels of adjacent elements are aligned by dowel pins. The columns are arranged in refueling regions each of which contains 7 columns, except at the outer edge of the core. The active core of a proposed 3000 MWt reactor contains 402 fuel columns and is surrounded by a permanent side reflector consisting of graphite (Figure 2.1). One quarter of the fuel will be replaced each year. The core is supported on graphite blocks and held in place by a lateral restraint structure. The core and primary coolant system are encased in a prestressed concrete reactor vessel.

The core is modeled mathematically in a simple cylindrical geometry, Figure 2.2. The same model and dimensions are used as in the General Atomic codes $\mathrm{CORCON}^{1}$ and SORS. ${ }^{2}$ The core is divided into concentric radial regions 
and 10 axial segments, one segment for each fuel element, and two for the top reflector. The properties of each radial region are calculated by averaging over the fuel elements in the corresponding annular portion of the reactor core. Thus, spatial variations within the core are partially taken into account.

\section{Hypothetical Accident Scenario and Data Used for the Calculations}

The data used in these calculations are taken from publications by General Atomic. Some of the data is based on experimental results. In other instances, for example, the temperature history of the core, the data has been predicted by computer codes. Table 3.1 summarizes some of the data and gives typical values for some of the parameters which would be expected in the course of the hypothetical accident.

\section{Inventory of Fission Products in the Core}

The inventory will depend on the time elapsed since the last refueling and also on the power level during the past four years. The amount of fission products will be a maximum just prior to refueling. Vanslager ${ }^{4}$ has calculated the inventory using the code RAD. The fission products are not uniformly dispersed but the concentration will vary from one part of the core to another. This variation is expressed by supplying a power factor for each axial node and a power factor for each radial node. The fraction of the inventory in a given portion of the core is then given by $P_{A} P_{R} V$, where $P_{A}$ and ${ }_{R}$ are the relevant axial and radial power factors, and $V$ is the volume of the portion of the core. The product ${ }{ }_{A}{ }{ }_{R}$ varies from .54 to 1.28 in the sample data. The power distribution in the different refueling regions has been calculated using core physics $\operatorname{codes}^{5}$ and the power factor for each radial region is calculated by averaging over the fuel rods included in the region. 


\section{Temperature History}

Schwartztrauber and Silady $^{1}$ have calculated the temperature evolution of each segment of the core using the code CORCON. The temperatures in the core rise slowly. The central part of the core is warmer than the outer portions. A coolant channel is modeled by dividing it into a number of segments, and the temperature is taken to be uniform within each segment. The change in temperature along the length of a coolant channel in the central portion of the core is shown in Figure 3.1 for two different times. It can be seen in Figure 3.1 that sharp discontinuities in the temperature are introduced at the boundary between two segments. However, the segments are chosen to coincide with the fuel elements so the thermal conduction from one element to another will be poorer than within one element. Figure 3.2 shows the evolution in time of the temperatures of these same segments. Segments 2 through 7 quickly reach the sublimation temperature of graphite, whereas the temperatures in the other segments of the active core rose more slowly. The temperature in the reflector blocks remains much lower. For the whole core, Figure 3.3 shows the average and maximum temperature versus time; after 10 hours the average temperature is about $3000^{\circ} \mathrm{F}$ and after 20 hours $4200^{\circ} \mathrm{F}$.

\section{Coolant Pressure}

Following a hypothetical pipe rupture the helium would escape into the containment. Macnab ${ }^{6}$ has calculated the change in pressure versus time in the code CONTEMPTG. If the containment remains intact the pressures in the PCRV and the containment reach equilibrium with a value of 39.8 psia after about 100 seconds. The pressure then falls to 29.0 psia at 20 minutes and 27.8 psia at 24 hours.

\section{Coolant Flow Rate}

In this hypothetical accident, it is assumed that there is no forced circu- 
lation, so that the flow of helium is due to natural convection caused by the hot core. Because of the large resistance to flow, the flow rate will be very slow. Schwartz et $a 1^{7}$ have estimated, using the code RECA, that the flow rate ranges from $.034 \mathrm{lb} / \mathrm{h}$ at about .1 hour, to $5.3 \times 10^{-5} \mathrm{lb} / \mathrm{h}$ at about 50 hours. The corresponding Reynolds numbers are 6.9 and 0.0041 so the flow is laminar and far below the transition to turbulent flow, which occurs at Reynolds numbers of about 2100. In calculations using SORS, Schwartz et al have used a conservative value of the flow rate of $5.67 \times 10^{3} \mathrm{gmole} / \mathrm{h}$. The Reynolds number depends on the temperature and so varies within the core. Using the above flow rate, the Reynolds number always lies in the range .1 to .5 .

\section{Diffusion Coefficients in Graphite}

Experimental values for the diffusion coefficients are available only for $\mathrm{Sb}$ and a few other elements. ${ }^{8}$ The data ${ }^{8}$ (Table 3.2) proposed by Norman makes use of a heuristic relationship between the activation energy for diffusion and the vaporization energy.

\section{Vapor Pressure}

Experimental vapor pressure data are available for many elements and their carbides. The data have been collected and reviewed by Norman. ${ }^{8}$ For $\mathrm{Cs}, \mathrm{Rb}$, $\mathrm{Ba}$ and Sr, Freundich isotherms are used above a critical concentration $\mathrm{C}_{0}$ and Langmuir isotherms are used for lower concentrations. For $\mathrm{C}>\mathrm{C}$ o

$$
\ln P=A+\frac{B}{T}+\left(A^{\prime}+\frac{B^{\prime}}{T}\right) \text { ln } C
$$

and for $\mathrm{C}<\mathrm{C}_{0}$

$$
\ln P=A+\frac{B}{T}+\left(A^{\prime}+\frac{B^{\prime}}{T}\right) \ln C_{0}+\ln \frac{C}{C_{0}}
$$

where $P$ is the pressure, $T$ is the temperature, $C$ is the concentration, $A, B, A^{\prime}, B^{\prime}$ 
are the vapor pressure constants, Table 3.4 .

For Cs a value of $C_{0}=0.078$ moles $/ \mathrm{m}^{2}$ has been observed and the same value is adopted for $\mathrm{Rb}, \mathrm{Ba}$ and $\mathrm{Sr}$. For the remaining elements an Arrhenius equation is used. Since the chemical form, in which the element is present, is not known, the vapor pressures of the free element and the carbide are added together in soRs. ${ }^{2}$ This assumption overestimates the vapor pressure and so, will overestimate the evaporation rate but will underestimate the deposition rate. If the surface coverage is less than a monolayer, the density of the vapor in equilibrium with the surface will be less than the saturated vapor density at the same temperature. It is assumed that the saturation vapor density is scaled by the same fraction as the surface coverage. Another parameter is thus introduced, namely the concentration of impurity corresponding to the monolayer coverage. This has been estimated by Norman ${ }^{8}$ from geometrical considerations based on the close packing of spheres with the appropriate atomic radii. So the expression used for the vapor pressure is for $C>C_{m}$

$$
\log P=A-B / T+A^{\prime}-B^{\prime} / T
$$

and for $\mathrm{C}<\mathrm{C}_{\mathrm{m}}$

$$
\log P=A-B / T+A^{\prime}-B / T^{\prime}+\log \left(C / C_{m}\right)
$$

where $\mathrm{P}$ is the pressure, $\mathrm{T}$ is the temperature, $\mathrm{C}$ is the concentration, $\mathrm{C}_{\mathrm{m}}$ is the concentration corresponding to a complete monolayer (Table 3.4), A, B are the vapor pressure constants for the element (Table 3.4), A', B' are the vapor pressure constants for the carbide (Table 3.4 ). 
4. Theory of Evaporation and Deposition in the Coolant Channels and Code $\underline{\text { EVAP }}$

After the fission product atoms have diffused through the graphite matrix to the coolant channel surface, they may escape from the surface and be carried along the coolant channel by the flowing helium. Further along the coolant channel, atoms may deposit back on the surface and then diffuse into the graphite. This cycle may be repeated several times, before an atom emerges out of the coolant channel into the upper plenum. At any place, the net loss by evaporation will depend on the local temperature and surface concentration of the graphite, the flow rate of the coolant and the partial pressure of the element in the coolant.

As the coolant flows up the coolant channels the fission products will evaporate from, or be deposited back on, the graphite wall depending on whether the partial pressure in the coolant is greater than, or less than, the vapor pressure at the surface of the channel. As the core heats up, material will initially evaporate from the hotter central segments and be redeposited on the cooler segments at the top and on the reflector. Eventually these segments heat up and the material reevaporates. The hypothetical accident scenario assumes that there is no forced circulation and so the coolant flow is induced by natural convection. Consequently, the flow rates of the coolant are low and the flow will be laminar flow. Typical values for the Reynolds number are given in Section 3 .

A third dimensionless number is important in the analysis of mass transfer. This number has no standard name so we will call it the "stagnation number," Sn. The stagnation number is defined as:

$$
S n=L / d \operatorname{Re} S c
$$


where $L$ is the length of the segment, $d$ is the diameter of the channel, Re is the Reynolds number, Sc is the Schmitt number.

The stagnation number can be rewritten as a ratio of the time that the coolant takes to traverse the channel to the time that an impurity atom takes to diffuse from the wall to the center of the channel. The reason for calling this dimensionless quantity the stagnation number is apparent, as it measures the degree of stagnation of the flow. In a stagnant container, an impurity in the fluid will be in equilibrium with the impurity deposited on the walls of the container. For flow through a channel, if the stagnation number is large there is ample time for many atoms to diffuse into the coolant stream during the time the coolant takes to flow the length of the channel. So at the exit from the channel the concentration of an impurity in the coolant will be in equilibrium with the impurity on the walls of the channel. For the case under consideration the driving force for mass transfer is the difference between the partial pressure of an impurity in the coolant and the vapor pressure of the impurity at the temperature of the graphite. How close the partial pressure, at the exit of a segment, is to the vapor pressure, within the segment, depends on the value of the stagnation number. Figure $4.1^{9}$ shows some data and theoretical predictions for flow through tubes. The pressure at the exit of a segment tends to the stagnant limit for large values of the stagnation number, and is within $5 \%$ of the limit for values of the stagnation number greater than about 0.2 . The stagnation number was calculated in SORSG $^{3}$ using the trial data. Sn varies from 247 to 2500 . Even if the flow rate is increased by a factor of 100 , the stagnation number is still within the limiting regime. Thus, for the flow conditions expected during the accident, the rate of transfer from coolant to the graphite, and vice versa, should be based on the expression 
for the stagnant limit.

\section{Code EVAP}

In the code EVAP, each channel is divided into $n$ segments, Figure 4.2, and the temperature of the graphite is taken to be uniform within each segment, Figure 3.1. For quasi-stagnant flow, the partial pressure of an impurity at the entrance to the $i^{\text {th }}$ segment is equal to the vapor pressure of the impurity in the $(i-1)^{\text {th }}$ segment. The partial pressure at the beginning of the channel can be zero, or can be given some other value to allow for recirculation of the impurity. The differential equation for the amount of an impurity $x_{i}$ in the $i^{\text {th }}$ segment is

$$
\frac{d x_{i}}{d t}=W\left(P_{i}-P_{i-1}\right) / P
$$

where

$$
\begin{aligned}
& x_{i}=\text { number of moles of the impurity in the graphite of the } i^{\text {th }} \text { segment } \\
& P_{i}=\text { vapor pressure of the impurity in the } i^{\text {th }} \text { segment (atm) } \\
& W=\text { coolant flow rate (moles/hour) } \\
& P=\text { ambient pressure (atm). }
\end{aligned}
$$

The $(n+1)$ coupled differential equations, for all the channels in one vertical region of the core, are integrated using Hammings method. This is a 4 step predictor-corrector method. A subroutine in the SSP 1 ibrary ${ }^{10}$ is used. This subroutine has a variable time step which is adjusted automatically during the integration to keep the error within a preset margin. The subroutine finds the first 3 values by a Runge-Kutta method. The maximum time step and the maximum error are supplied in the input. Radial variations within the core are taken into account by the subdivision of the core into several radial regions. The same procedure is repeated for the coolant channels in the next radial region. After calculating the release into the upper plenum from each of the radial 
regions the total amount released into the plenum is found.

Concentration of the Fission Products at the Surface of a Channel

The vapor pressure, of the fission product, close to the surface of a channel, depends on the concentration of the fission product at the surface of the graphite. Diffusion will occur in the graphite to even out any concentration gradients. Initially almost all the fission products are contained within the fuel particles. As the temperature rises the fission products escape from the fuel particles and spread throughout the graphite matrix. So initially, the concentration at the surface of a coolant channel is less than the concentration in the interior of the graphite. As the core heats up, fission products will evaporate from the hotter central part of the core and redeposit on the cooler upper segments and on the top reflector. The concentration at the surface of these latter segments will thus be higher than the concentration in the interior of the graphite. A complete treatment of the problem would be very complex, as diffusion and evaporation should be treated simultaneously. In the first version of EVAP, the simple assumption is made that the surface concentration, for a segment, is equal to the average concentration, within that segment. It is assumed that, at the temperatures at which evaporation occurs, the diffusion rate within the graphite is sufficiently rapid that the concentration profile is always uniform. In other words, as atoms evaporate from, or are deposited on, the surface, migration to, or from, the interior occurs immediately to maintain an even concentration.

In order to examine the realm of validity of this approximation, calculations were made to determine rough guidelines for the time scale required for diffusion. A simple model, for which a solution is available, was considered. The geometry of the core is complex so the graphite matrix is modeled as a cylinder surrounding the fuel hole. The assumption in the code is that evaporation is a 
very much slower process than diffusion. Taking this assumption to an extreme, the evaporation rate would be relatively so slow that the surface would be almost an impermeable barrier. For a rough estimate of the time required to establish an approximately uniform concentration, we will use the solution of the problem of the diffusion in a cylinder which has an impermeable surface. ${ }^{11}$ The initial condition is that the impurity is uniformly distributed within the fuel rod. The time required for the ripple in the concentration to become less than about $5 \%$ was calculated. Since diffusion is an activated process the time depends very sensitively on the temperature, Figure 4.3.

Table 4.1 shows the estimated diffusion times at two critical temperatures, $2270^{\circ} \mathrm{K}$ and $3640^{\circ} \mathrm{K}$. At $2270^{\circ} \mathrm{K}$, most of the fuel particles have failed and so diffusion from the fuel rods has commenced; $3640^{\circ} \mathrm{K}$ is the sublimation temperature of graphite, and is attained after 20-30 hours by the hotter portions of the core. At the lower temperatures, the time required for $\mathrm{Rb}$ and $\mathrm{Cs}$ to spread out through the graphite web is less than .02 hour and for $\mathrm{Eu}, \mathrm{Sr}, \mathrm{Ba}$ and $\mathrm{Sb}$ it is less than .5 hour. So, for all these elements it is a good approximation to assume that the concentration is uniform. For Sm and Pm, it would take about $1-3$ hours, at the fuel failure temperature, for the concentration at the coolant channel surface to rise. However, at higher temperatures less time is required and at $3640^{\circ} \mathrm{K}$ less than about .1 hour is needed. So, for these two elements, it is probably still a good approximation in the temperature range over which evaporation occurs. The next two elements, Nd and $\operatorname{Pr}$, require .6 hour and 1.5 hours, respectively, at $3640^{\circ} \mathrm{K}$. So for $\mathrm{Nd}$ and $\operatorname{Pr}$ the assumption of a uniform concentration in the graphite is tentative. For the remaining elements, diffusion is slower, so variations in the concentration within the graphite should be taken into account. For example, about 35 hours at the sublimation temperature of graphite would be required for the Ce to diffuse out of the fuel rods and spread uniformly through 
the graphite, so assumption of a uniform concentration would overestimate the vapor pressure. Thus, the present version of EVAP is most suitable for the moderately volatile elements, those elements more mobile than Pr.

\section{Radioactive Decay of the Fission Products}

EVAP does not include a decay term in the differential equations. A correction factor can be applied to the results, and this will be adequate for most nuclides.

1. For isotopes with no long lived precursor, multiply the initial activity by a factor of $e^{-\lambda t}$ where $\lambda$ is the decay constant.

2. If an isotope with a short lifetime has a precursor whose lifetime is relatively much longer, then the quantity of the isotope at any place depends on the amount of the parent at that place. So the migration of the parent determines the dispersal of the daughter isotope and the activity of the daughter approximately equals that of the parent.

Almost all nuclides fall into one of these two categories.

\section{Results of the Calculations Using EVAP}

EVAP has been used to calculate the release of the moderately volatile elements, $\mathrm{Rb}, \mathrm{Cs}, \mathrm{Sr}, \mathrm{Ba}, \mathrm{Sb}, \mathrm{Eu}, \mathrm{Sm}, \mathrm{Pm}, \mathrm{Nd}$ and $\mathrm{Pr}$, and the migration of these elements along the coolant channels. The calculations used the data which Schwartz, et al. ${ }^{2}$ used in the analysis of a loss of coolant accident and which is described in Section 3. Since the values of some important parameters are not known accurately during the course of the accident, the calculations were repeated for several possible values of these parameters.

Results for Different Elements

Figure 5.1 shows the fraction, of the total amount of a fission product in the core, which escapes into the upper plenum versus time. Essentially no release 
occurs until about 20 hours after the onset of the accident. Some of even the most volatile elements under consideration remain in the cooler parts of the core longer than 50 hours. For the least volatile elements, Pm-Nd, less than $1 \%$ escapes from the core in 50 hours. However, these elements have migrated within the core and Figure 5.2 shows the amount of these elements in the top reflector versus time. By 50 hours, about $7 \%$ of the Nd has reached the reflector. For elements which diffuse more slowly than Nd, use of EVAP would overestimate the evaporation rate from the segments containing fuel elements, so even less of these elements would reach the top reflector at any time.

The temperature history ${ }^{1}$ of the coolant channels varies in different regions of the core. Figures 5.1 and 5.2 show the results for the whole core divided into 15 radial regions. Figures 5.3 and 5.4 show similar curves which apply to the channels in the central region of the core, which is one of the hotter regions. Naturally, there has been more migration within this portion of the core and all the $\mathrm{Sb}, \mathrm{Rb}$ and $\mathrm{Cs}$ present in this region have been released by 50 hours.

\section{Redistribution of the Fission Products Among the Segments of the Coolant} Channels

Figures 5.5 through 5.8 show the migration of a moderately volatile element Eu and a less volatile element Pr. Each region of the core is divided into 10 axial segments of which number 1 is the lowest segment, and numbers 9 and 10 are the reflector segments. The hotter segments start losing Eu after about 9 hours and $\operatorname{Pr}$ after about 19 hours. The fission products first build up in segments 7 and 8 then reevaporate and move into the top reflector. Figures 5.5 and 5.7 show the results for each axial subdivision of the whole core. Figures 5.6 and 5.8 show the results for the segments in the central region of the core. The corresponding temperature ${ }^{1}$ sequences for this region of the core are shown in Figure 3.2. In using EVAP, the inherent assumption is made that, at the time at 
which evaporation becomes feasible, the element concerned has dispersed throughout the graphite. Initially the fission products are contained within fuel particles. For the central region of the core it has been calculated, using SORS, ${ }^{3}$ that most of the fission products escape from the fuel particles within the time interval of 4 to 8 hours. Thus, for these elements the detailed timing of their escape from the fuel particles should have little effect on their migration along the coolant channels.

\section{Effect of Different Temperature Sequences}

The rate at which an element can migrate along a coolant channel depends on the temperature history of the segments of the channel. Figure 5.9 shows the fraction of Eu which escapes into the upper plenum from the coolant channels in the different regions of the core. The core has been divided into 14 radial regions and region number 1 is the central region. The release curve is sensitive to the temperature history of a region, so there is substantial variation from the inner part of the core to the cooler outer regions.

\section{Effect of the Flow Rate}

In the present calculation we have assumed that the fission products are carried along the coolant channel by the slowly moving stream of helium. The rate of flow of the helium varies in the course of the accident and depends on the natural circulation set up by the temperature imbalance between the core and the rest of the primary coolant circuit. Most of the calculations use the same flow rate as was used in SORS, ${ }^{2} 5.67 \times 10^{3}$ moles/hour. Even if the flow rate were zero, some migration of fission products would still occur, because of the temperature gradients in the coolant channels. A temperature gradient always causes a flow of matter as well as energy. This is known as thermal diffusion. In addition, the walls of the channel prescribe the value of the vapor density of an impurity close to the surface of the channel. Because of the possibility of 
deposition or evaporation, the vapor density at the surface of the channel equals the saturated vapor density at the local temperature. So the temperature gradients induce density gradients and hence ordinary diffusion will also occur. Both thermal diffusion and ordinary diffusion will cause migration towards the cooler parts of the core. In addition, direct migration could take place from one fuel element to another. All of these mechanisms could be relatively important at very slow flow rates.

The flow rate in the core is a parameter which is not well known. Figures 5.10 through 5.12 show the consequences of using a different flow rate. The results are for the central region of the core. Figures 5.10 and 5.11 show that changing the flow rate by even a factor of two causes a big shift in the release curves predicted for $\mathrm{Eu}$ and $\mathrm{Pr}$. If the actual flow rate after about 30 hours is much less than the value estimated by Schwartz, et $a 1 .^{2}$ then convection may no longer be the dominant mechanism for transport along the coolant channel.

\section{Effect of Pressure}

Another important parameter is the pressure of the helium in the primary coolant circuit. The value of the pressure will depend on whether the containment has been breached or vented. Most of the calculations have been performed for a pressure of $1 \mathrm{~atm}$. Figure 5.13 compares the fraction of Eu released for pressures of 1 and $2 \mathrm{~atm}$. The curves are for the central region of the core. The same flow rate was used in both calculations to isolate the effect of the pressure, although in practice a change in the ambient pressure would also probably result in a different flow rate. If the containment remains intact and the pressure during the accident has the value of about 28 psia, which is predicted

by CONTEMPTG, ${ }^{6}$ then the migration of the fission products will tend to be retarded by 3-4 hours. 


\section{Effect of Vapor Pressure Calculation}

The chemical form of the fission products in the graphite at high temperatures is not known. It is assumed that the graphite remains intact and is not attacked by the fuel. Chemical compounds may form by the fission products with each other or with other elements in the fuel. In such a case, the migration of an element will be determined by the vapor pressure of the compounds and the possibility of chemical reactions. Since the chemistry is unknown it is assumed that the fission products are present in elemental form or as carbides. The carbides generally have a lower vapor pressure than the elements. The total vapor pressure was taken to be the sum of the vapor pressure of the element and the carbide in the previous calculations. The calculations were repeated for Eu using each of these vapor pressures in turn. Neglecting the vapor pressure of the carbide does not affect the results, since the vapor pressure of the $\mathrm{EuC}_{2}$ is much less than that of $\mathrm{Eu}$ in the temperature range of interest. If it is assumed that $\mathrm{EuC}_{2}$ is formed, then no release occurs in 50 hours; some of the $\mathrm{Eu}$ is carried into the top reflector only. Figure 5.14 shows the fraction of Eu released using the vapor pressure of Eu and also the fraction in the top reflector using the vapor pressure of $\mathrm{EuC}_{2}$.

Another important parameter in the calculation of the vapor pressure is the amount of a fission product corresponding to a monolayer coverage of the graphite surface. This was estimated by Norman ${ }^{8}$ on a purely geometrical basis. Several fission products are simultaneously present in the graphite and will be competing for surface sites. Thus, the vapor pressure of an element will be higher when other species are present, than when it is the sole impurity present. Figure 5.15 shows the release curve for graphite using the monolayer concentra-

tion suggested by Norman ${ }^{8}$ and for a half of this value. The value chosen for the concentration corresponding to a complete monolayer only affects the calcu- 
lated vapor pressure when the amount of the impurity in a segment is lower than that required for a complete monolayer. Figure 5.15 shows that the release curve is sensitive to the choice of the number of surface sites.

\section{Effect of Diffusion}

The present version of EVAP assumes that diffusion is so rapid that the concentration in a segment is always uniform. Like the coatings of the fuel particles, the graphite web is a barrier to the motion of the fission products, and time is required for the fission products to diffuse from the fuel holes to the coolant channels. The importance of the time delay necessitated by the fuel particle coatings and diffusion can be assessed by artificially imposing a time delay on the process of migration along the coolant channel. Figure 5.6 shows that most of the Eu leaves segments $1-6$ of the central region, between 10 and 20 hours after the accident. The calculation was repeated but the amounts of Eu in each segment were maintained at the initial values until 20 hours whereupon migration was permitted. The amount of Eu in each segment very quickly readjusted itself to the value found previously. By 25 hours the agreement was within a few percent. The release curve into the upper plenum was essentially the same for both calculations. So the details of the diffusion process at the earlier stages of the accident probably do not affect the final release curves very much.

\section{Reflector Approximation}

The fission products in the lower part of the core are carried up the coolant channels and deposit on the top reflector. They cannot reevaporate and escape into the upper plenum until the temperature of the top reflector has risen sufficiently so that the vapor pressure is high. So the top reflector acts as a trap which catches the fission products, and the final stage of release from the reflector depends primarily on the temperature history of the reflector. A very simple 
approximation for quick calculations, would be to assume that all the atoms of a given fission product were trapped in the reflector right from the start of the calculation and then to calculate the ensuing release rate into the upper plenum. Figure 5.16 shows the results of such a calculation for three typical elements, $\mathrm{Rb}$, Eu and $\mathrm{Sm}$. The results of this very simplistic calculation of the release rates are within a few per cent of the results calculated using the whole code.

\section{Conclusions}

Following a hypothetical loss of cooling accident, there is a conceivable mechanism by which nonvolatile fission products could escape from the core; this is that the atoms evaporate into the coolant channels and are swept up the channels by the helium. The flow rate quoted by schwartz, et al. ${ }^{2}$ is so slow that quasi-stagnant conditions would be expected. The most important parameter, of those investigated, which governs how fast the fission products can escape from the core is the flow rate of the helium. Two other parameters which also affect the release curve are the ambient pressure and the temperature sequence. The timing of the release varies considerably for different elements. Since the top reflector traps the fission products which have originated in other parts of the core, the final release into the upper plenum depends primarily on the temperature history of the top reflector. The earlier stages of the migration, the release from the fuel, the diffusion through the graphite, and the redistribution among the other segments of the core do not affect appreciably the final release curve, for the conditions considered. 


\section{References}

1. K. E. Schwartztrauber and F. A. Silady, CORCON: A program for analysis of HTGR core heatup transients, GA-A-12868, 1974.

2. M. H. Schwartz, D. B. Sedgeley and M. M. Mendonca, SORS: Computer programs for analyzing fission product release from HTGR cores during transient temperature excursions, GA-A-12462, 1974, and supplements.

3. J. M. Dickey, An analysis of SORS, computer programs for analyzing fission product release from HTGR cores during transient temperature excursions, BNL-NUREG-50806, 1978.

4. F. E. Vanslager, RAD2: A computer program for calculating fission product radioactivities, GAMD-6519, 1965.

5. C. J. Hami1ton, HTGR power distributions, GA-A-13007, 1974.

6. D. I. Macnab, The CONTEMPT-G computer program and its application to HTGR containments, GA-A-12692, 1974.

7. H. W. Chi and G. J. Malek, Description of the reactor emergency cooling analysis code, RECA, GA-10273, 1970.

8. J. H. Norman, Review of vapor pressures and diffusion coefficients of certain HTGR core materials and fission products for use in reactor accident calculations, GA-A-12634, 1974.

9. T. K. Sherwood and R. L. Pigford, Absorption and Extraction, McGraw Hill, 1952.

10. IBM, System 1360 Scientific Subroutine Package, 1966.

11. J. Crank, The Mathematics of Diffusion, Oxford Univ. Press, 1975.

\section{Acknowledgement}

I thank G, Searles for typing this report and J, Colman and J. F. Beerman for assistance with the $\operatorname{CDC} 7600$. 


\section{Table 3.1}

Data for the proposed design of a 3000 MWt HTGR and typical values of the parameters used in the calculations. The data is taken from relevant publications by General Atomic:

Length of a fuel element

Diameter of a coolant channel

Distance from the center of the fuel hole to the center of the coolant channel

Number of coolant channels in one standard fuel element

Mass of the graphite in the active core

Mass of the graphite in the top reflector

Pressure of the coolant

Flow rate of the coolant

Reynolds number

Schmidt number

Stagnation number
$79.3 \mathrm{~cm}$.

$2.1 \mathrm{~cm}$.

$2.3 \mathrm{~cm}$.

72

$2.86 \times 10^{8} \mathrm{~g}$.

$5.93 \times 10^{7} \mathrm{~g}$.

1 atm.

$5.67 \times 10^{3}$ moles/h.

0.2

1.6

1000 
Table 3.2

Power Factors ${ }^{2}$

\begin{tabular}{ccc} 
Section & Axial & Radial \\
\hline 1 & 0.672 & 0.987 \\
2 & 0.901 & 1.03 \\
3 & 0.973 & 1.10 \\
4 & 1.01 & 1.10 \\
5 & 1.16 & 1.14 \\
6 & 1.14 & 1.17 \\
7 & 1.11 & 1.17 \\
8 & 1.04 & 1.10 \\
9 & 0.0 & 1.06 \\
10 & 0.0 & 1.06 \\
11 & - & 0.921 \\
12 & - & 0.945 \\
13 & - & 0.945 \\
14 & - & 0.780
\end{tabular}


Table 3.3

Diffusion Coefficients for Elements in Graphite (a) (Taken from Norman ${ }^{8}$ )

\begin{tabular}{|c|c|c|c|}
\hline Element & A & & $B$ \\
\hline$Y$ & 0.74 & 14.2 & \\
\hline $2 r$ & 1.19 & 22.8 & \\
\hline $\mathrm{Nb}$ & 1.32 & 25.5 & \\
\hline Mo & 1.00 & 19.2 & \\
\hline $\mathrm{Tc}$ & 1.02 & 19.6 & \\
\hline $\mathrm{Ru}$ & 0.91 & 17.5 & \\
\hline $\mathrm{Rh}$ & 0.77 & 14.8 & \\
\hline $\mathrm{Pd}$ & 0.52 & 10.1 & \\
\hline $\mathrm{Sb}$ & 0.35 & 6.8 & \\
\hline $\mathrm{La}$ & 0.75 & 14.4 & \\
\hline $\mathrm{Ce}$ & $0.84(0.55)$ & 16.2 & $(10.5)$ \\
\hline $\mathrm{Pr}$ & 0.63 & 12.0 & \\
\hline Nd & 0.56 & 10.7 & \\
\hline $\mathrm{Pm}$ & 0.44 & 8.5 & \\
\hline $\mathrm{Sm}$ & 0.39 & 7.6 & \\
\hline $\mathrm{Eu}$ & 0.33 & 6.4 & \\
\hline Th & $1.03(0.98)$ & 19.8 & $(18.8)$ \\
\hline $\mathrm{Pa}$ & 1.13 & 21.7 & \\
\hline $\mathrm{U}$ & 0.81 & 15.6 & \\
\hline $\mathrm{Pu}$ & 0.55 & 10.6 & \\
\hline $\mathrm{Sr}$ & $0.34(0.67)$ & 6.5 & $(6.8)$ \\
\hline $\mathrm{Ba}$ & $0.35(0.12)$ & 6.7 & $(7.0)$ \\
\hline $\mathrm{Cs}$ & 0.21 & 4.1 & \\
\hline $\mathrm{Rb}$ & 0.21 & 4.1 & \\
\hline
\end{tabular}

(a) Literature values are shown in parentheses.

$-\log _{10} D=A+\frac{B \times 10^{3}}{T}$,

where $D$ is in $\mathrm{cm}^{2} / \sec$ and $T$ is in ${ }^{\circ}$. 
Table 3.4

Vapor Pressure Constants

(Taken from Norman ${ }^{8}$ )

$\begin{array}{ccccccc}\text { Element } & \mathrm{A} & \mathrm{B} & \mathrm{A}^{\prime} & & \mathrm{B}^{\prime} & \mathrm{C} \\ \mathrm{Ba} & 6.49 & -33.7 & -1.30 & 7.55 & 0.078 \\ \mathrm{Sr} & 8.67 & -36.1 & -0.572 & 4.59 & 0.078 \\ \mathrm{Cs} & 7.8 & -29.84 & -0.235 & 1.87 & 0.078 \\ \mathrm{Rb} & 9.33 & -31.06 & -2.23 & 6.99 & 0.078 \\ \mathrm{Sb} & 5.35 & 12.4 & 5.13 & 9.0 & 19.0 \\ \mathrm{Eu} & 3.28 & 11.6 & 6.66 * & 26.2 * & 12.1 \\ \mathrm{Sm} & 3.72 & 13.8 & & & 14.6 \\ \mathrm{Pm} & 3.93 & 15.5 & & & & 14.6 \\ \mathrm{Nd} & 3.47 & 19.5 & 7.00 & 30.4 & 14.5 \\ \mathrm{Pr} & 4.37 & 21.9 & 7.59 & 31.3 & 14.5\end{array}$

For $\mathrm{Ba}, \mathrm{Sr}, \mathrm{Cs}, \mathrm{Rb}, \mathrm{C}$ is the concentration, in $\mu \mathrm{moles} / \mathrm{m}^{2}$, corresponding to a transition to Langmuir isotherms. For the remaining elements $C$ is the estimated concentration, in umoles/gram of graphite, corresponding to a surface concentration of 1 monolayer.

The constants $A, A^{\prime}, B, B^{\prime}$ are defined in Eqs. 3.1 and 3.2 .

$*$ For $\mathrm{Sb}_{2}$. 
Table 4.1

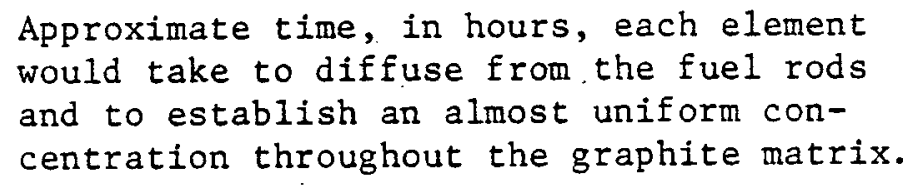

Element

$2270^{\circ} \mathrm{K}$

1. $9 E-02$

1. $9 \mathrm{E}-02$

2. $5 E-01$

2. $9 E-01$

3. $6 E-01$

4. $0 E-01$

9. $9 E-01$

2. $8 \mathrm{E}+00$

1. $7 \mathrm{E}+01$

3. $0 E+01$

$3.4 E+01$

1. $5 \mathrm{E}+02$

1. $8 \mathrm{E}+03$

2. $2 \mathrm{E}+03$

3. $5 \mathrm{E}+03$

8. $7 E+03$

1. $7 \mathrm{E}+04$

7. $5 \mathrm{E}+04$

5. $2 E+05$

8. $1 E+05$

1. $0 \mathrm{E}+06$

8. $8 \mathrm{E}+06$

3. $1 \mathrm{E}+07$

$6.5 \mathrm{E}+08$ $3640^{\circ} \mathrm{K}$

3. $9 E-03$

3. $9 \mathrm{E}-03$

2. $2 \mathrm{E}-02$

$2.4 E-02$

2. $8 \mathrm{E}-02$

3. $0 \mathrm{E}-02$

5. $4 \mathrm{E}-02$

1. $1 \mathrm{E}-01$

3. $6 \mathrm{E}-01$

5. $2 \mathrm{E}-01$

5. 7E-01

1. $5 \mathrm{E}+00$

7. $9 \mathrm{E}+00$

9. $2 \mathrm{E}+00$

1. $2 E+01$

2. $3 E+01$

3. $5 \mathrm{E}+01$

9. $4 \mathrm{E}+01$

$3.4 E+02$

4. $6 \mathrm{E}+02$

5. $3 \mathrm{E}+02$

2. $2 \mathrm{E}+03$

5. $1 E+03$

3. $8 \mathrm{E}+04$ 


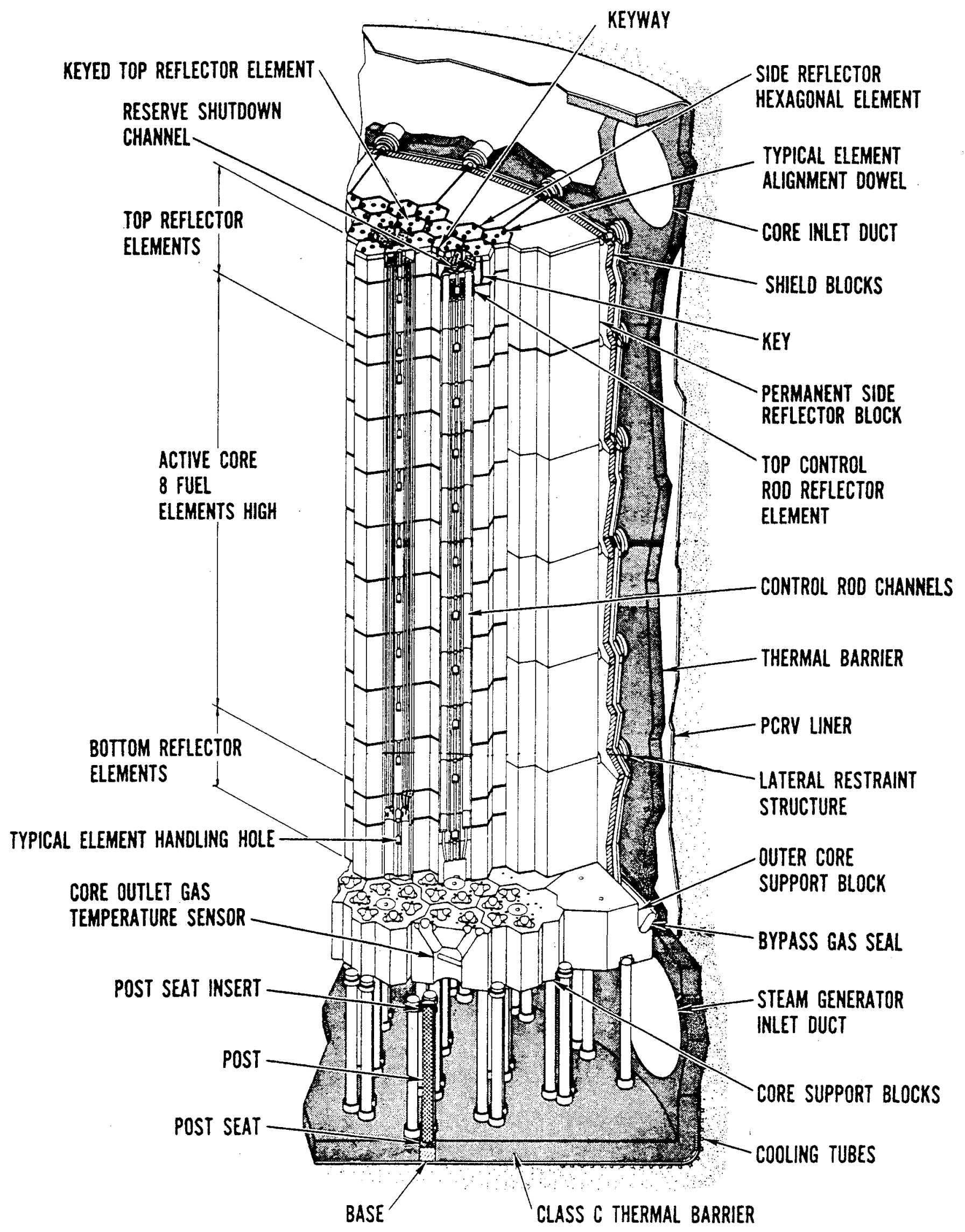




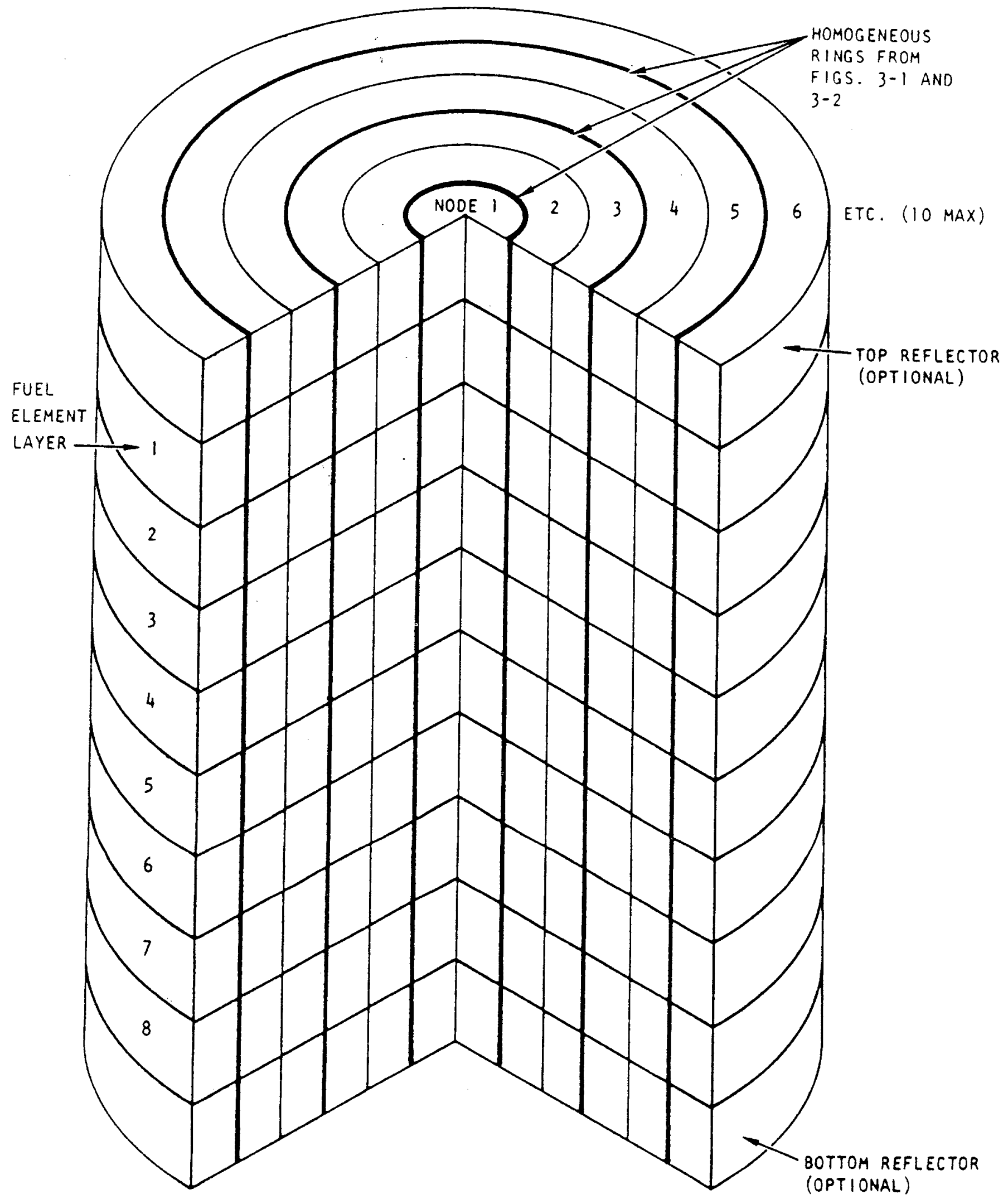

Figure 2.2 


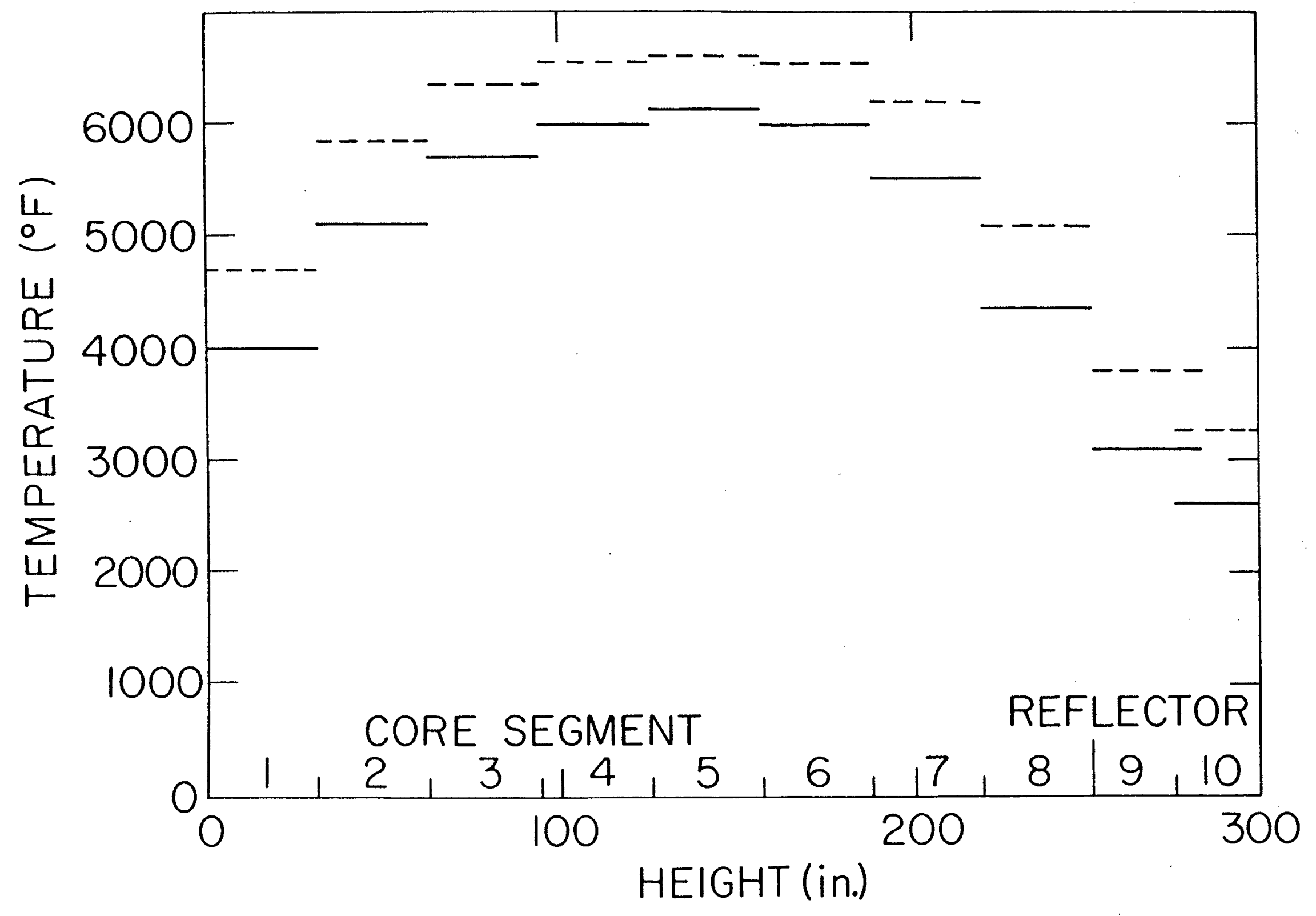

Figure 3.1 


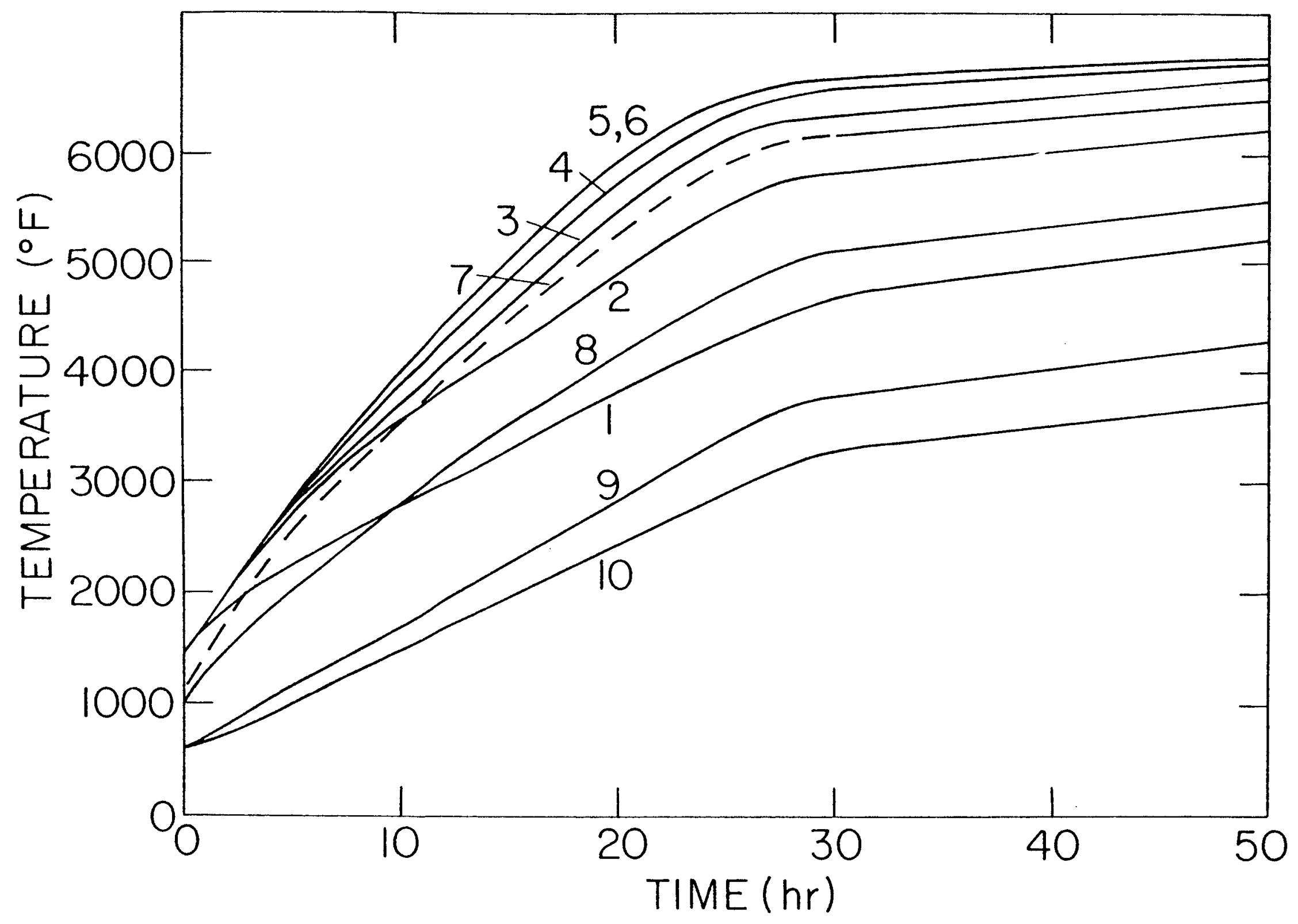

Figure 3.2 


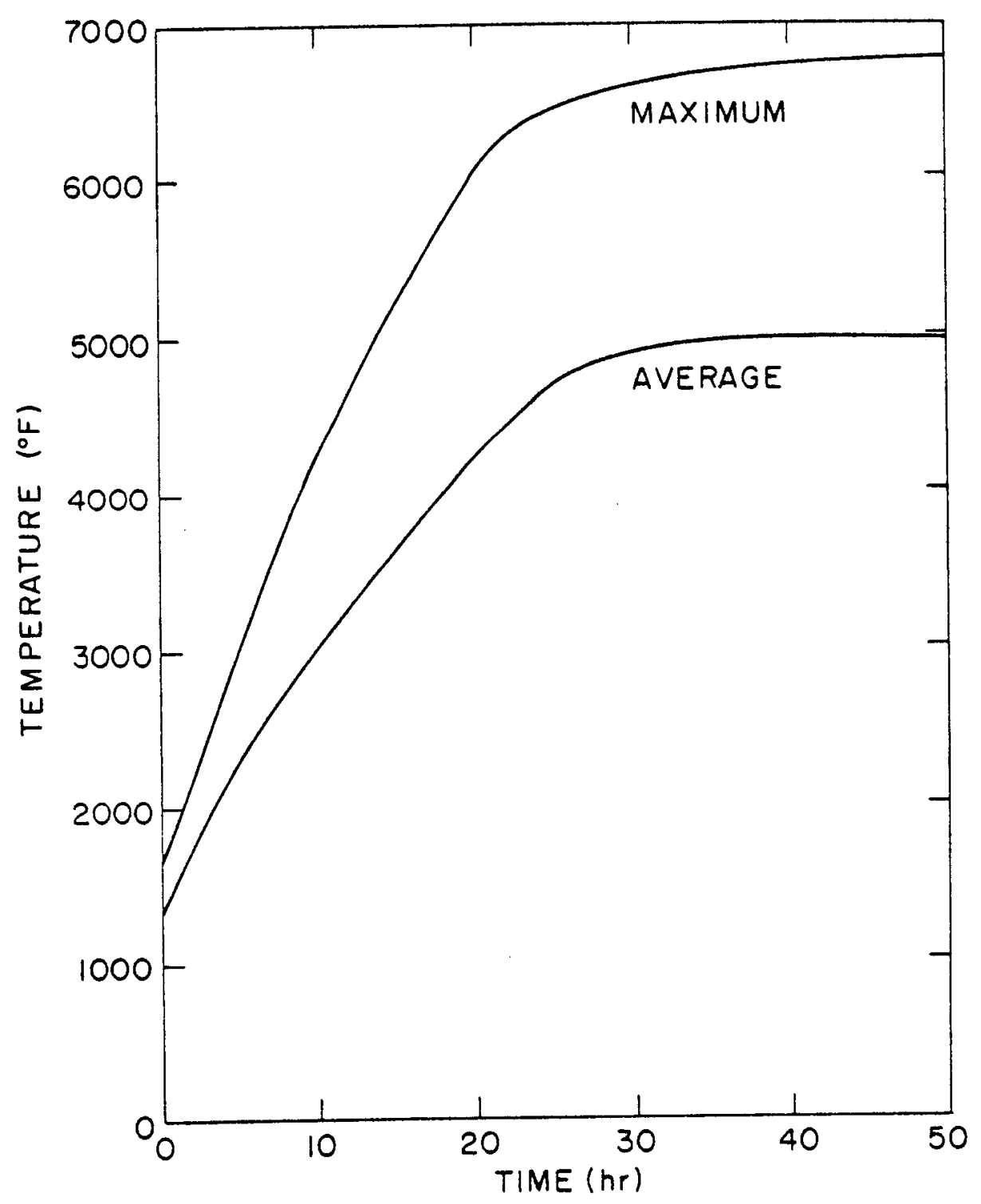

Figure 3.3 
T.K. Sherwood and R.L. Pigford

\section{AbSORPtion AND EXtRAction P. 82}

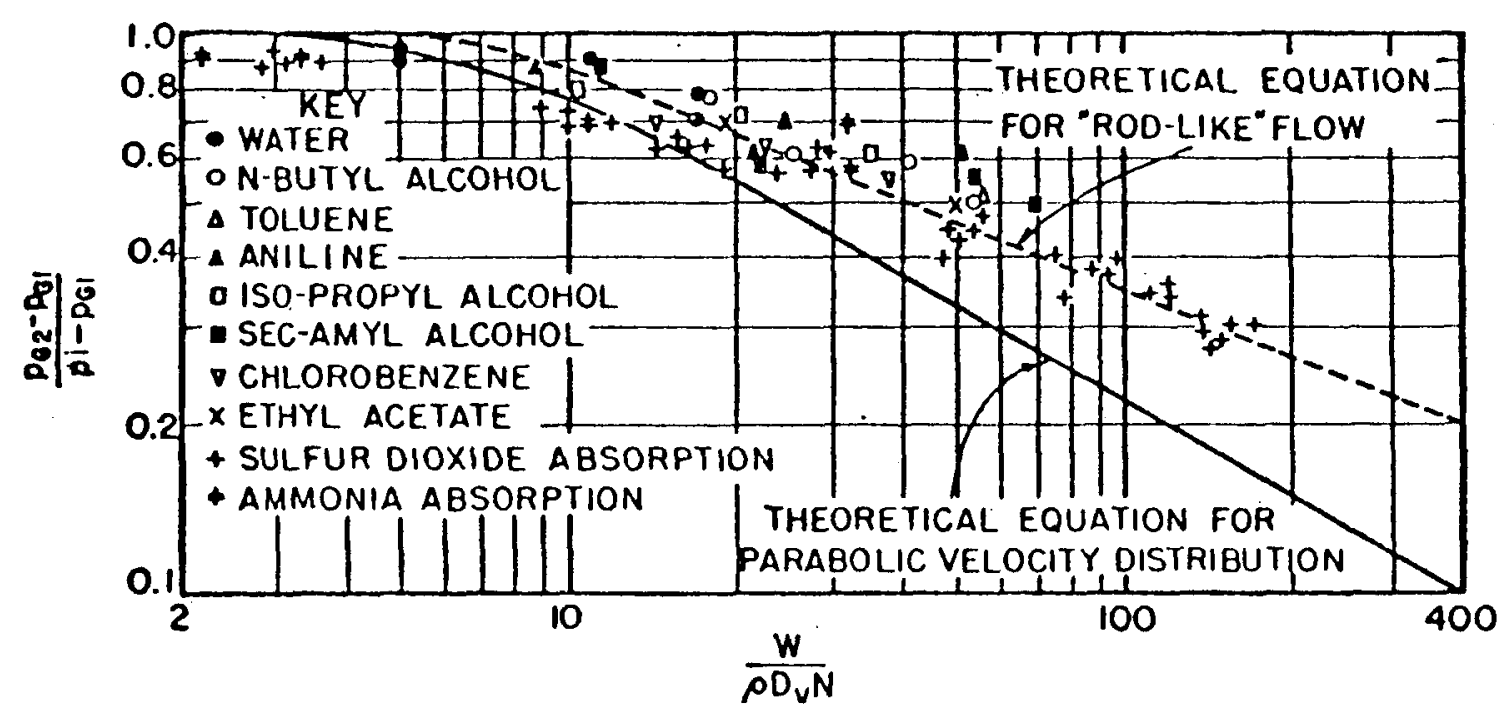

Data on mass transfer in a wetted-wall tower with streamline flow.

$x$ AXIS is $\frac{\text { II }}{4}$ (1/'StAgnation NUMBER') $\equiv$ GRAETZ NUmber

$Y$ AXIs is $\frac{P_{2}-P_{1}}{V P-P_{1}}$ 


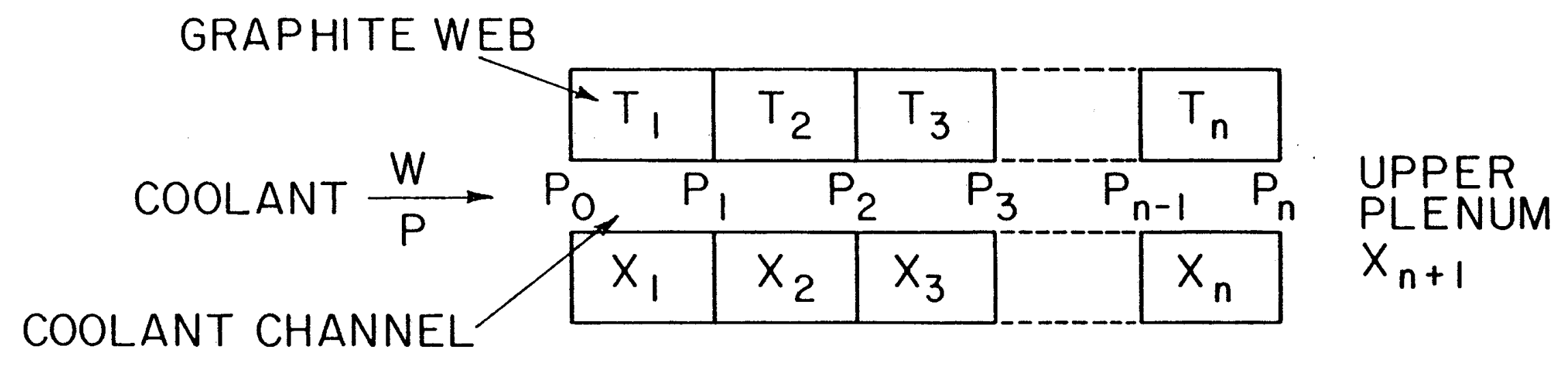

Figure 4.2 


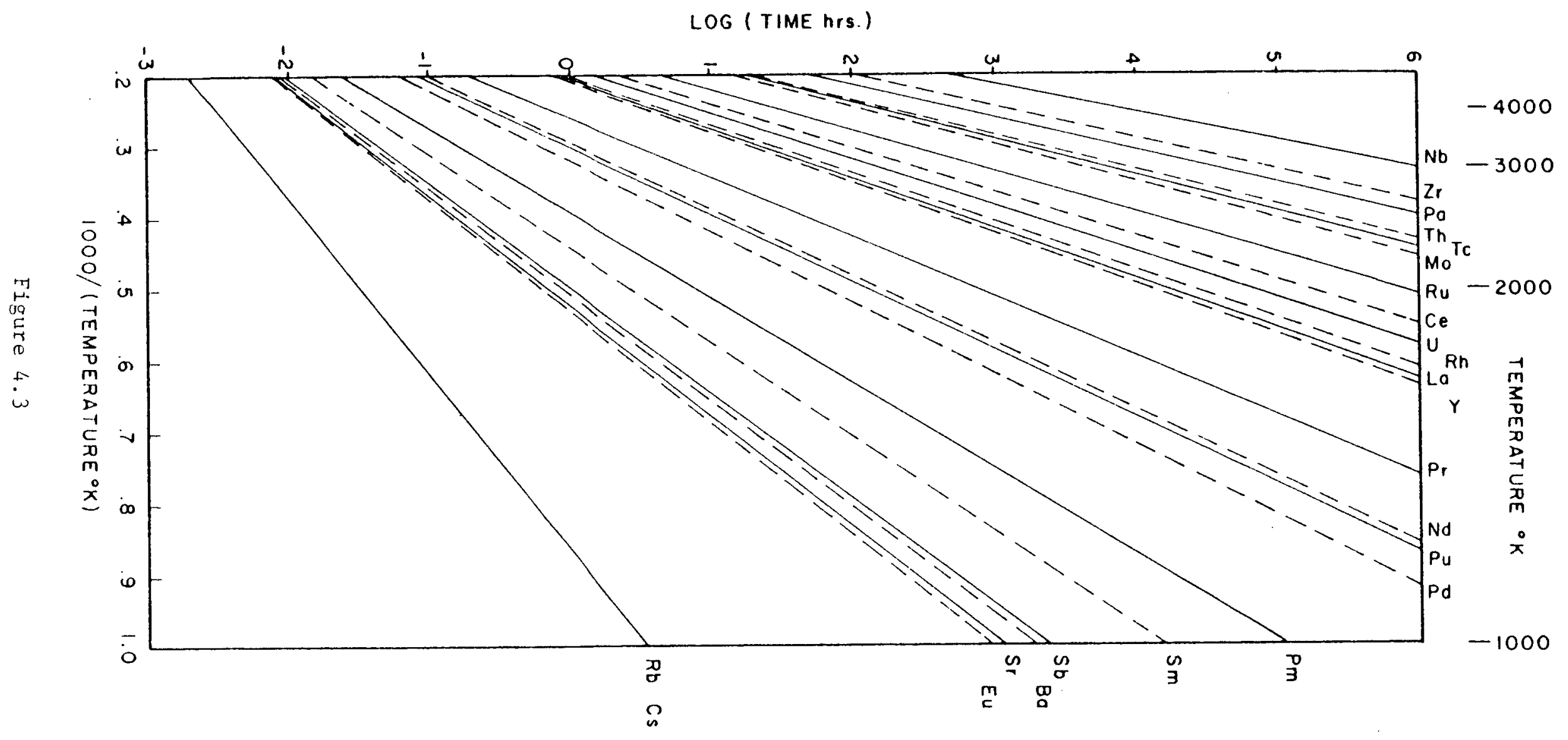




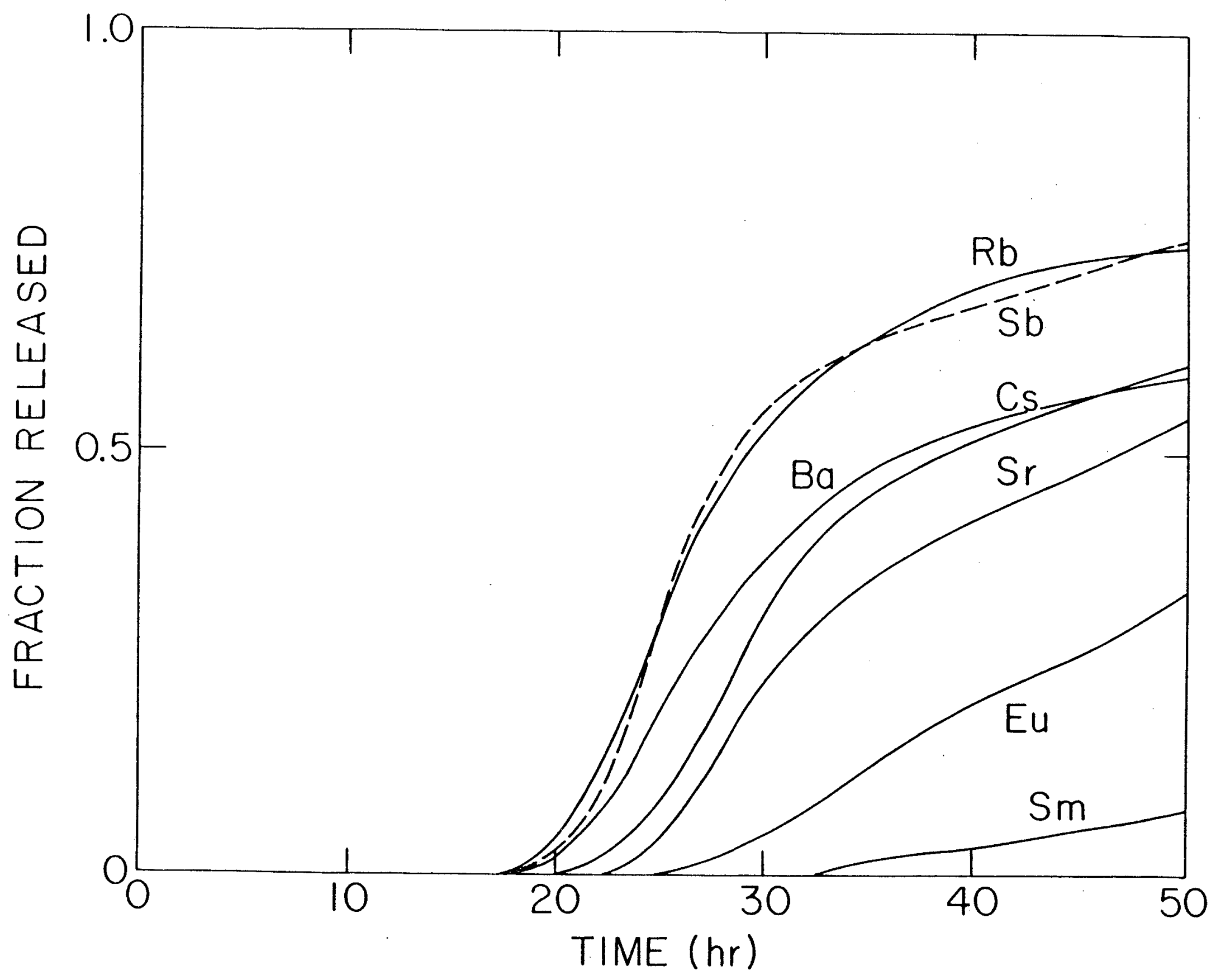

Figure 5.1 


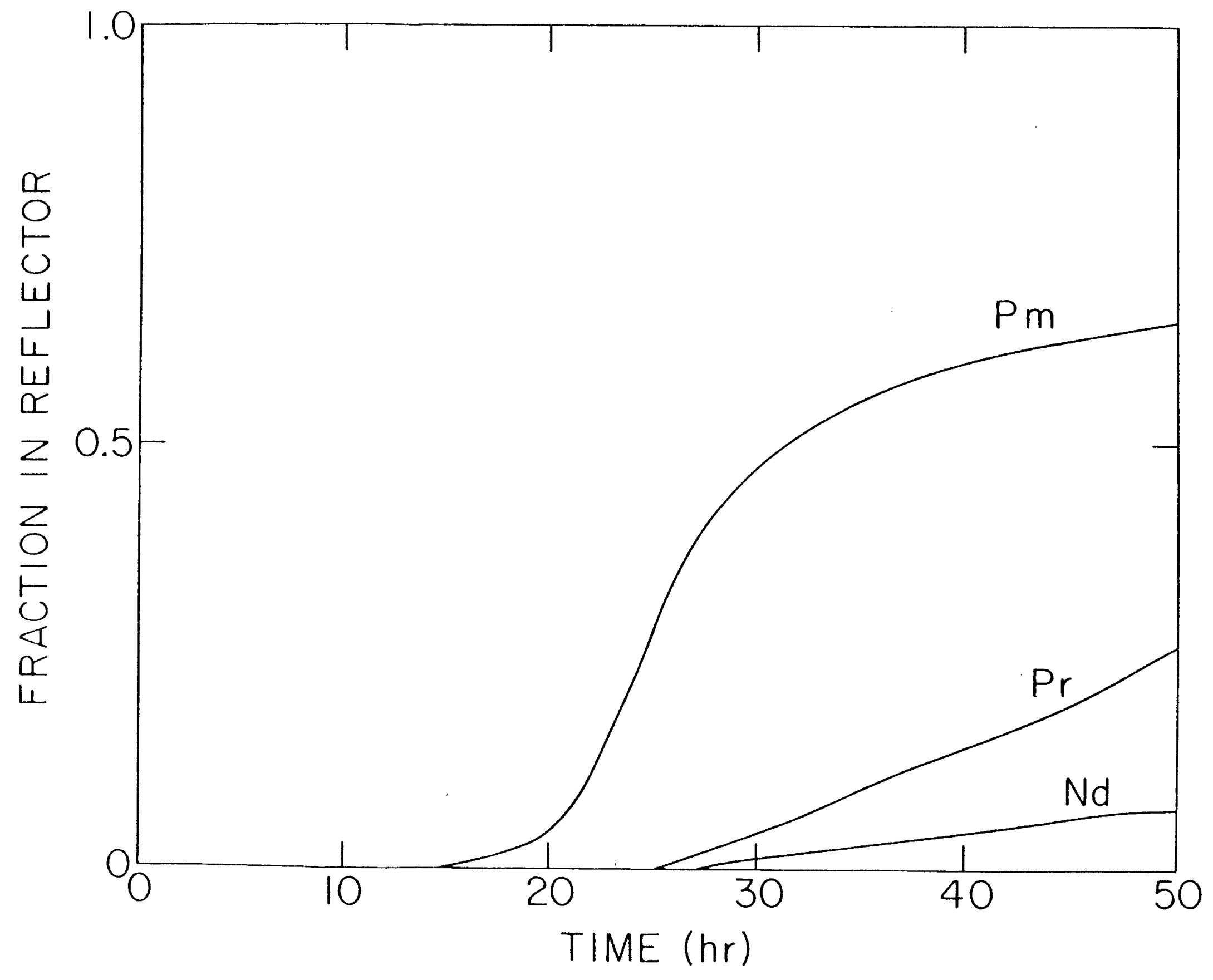

Figure 5.2 


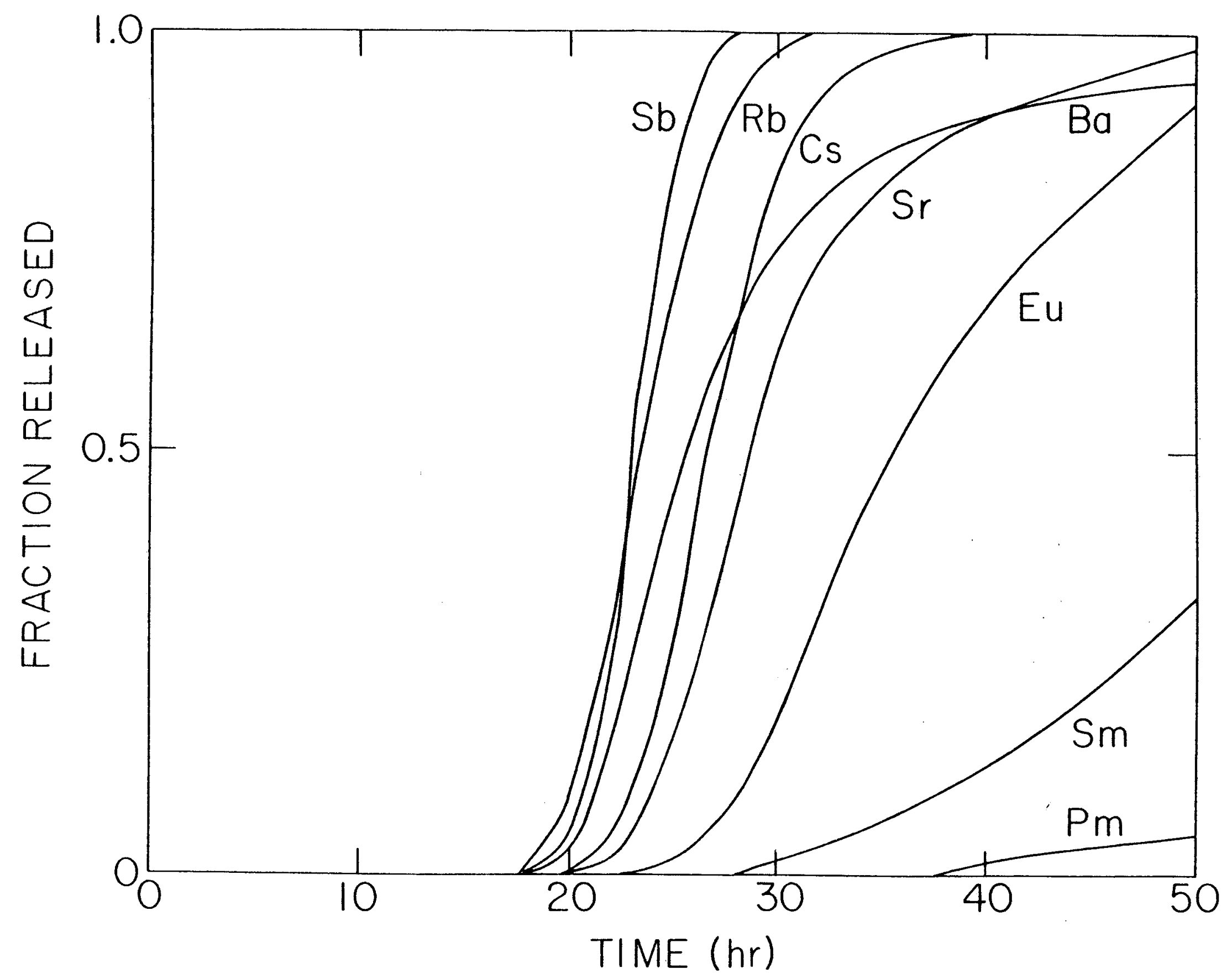

Figure 5.3 


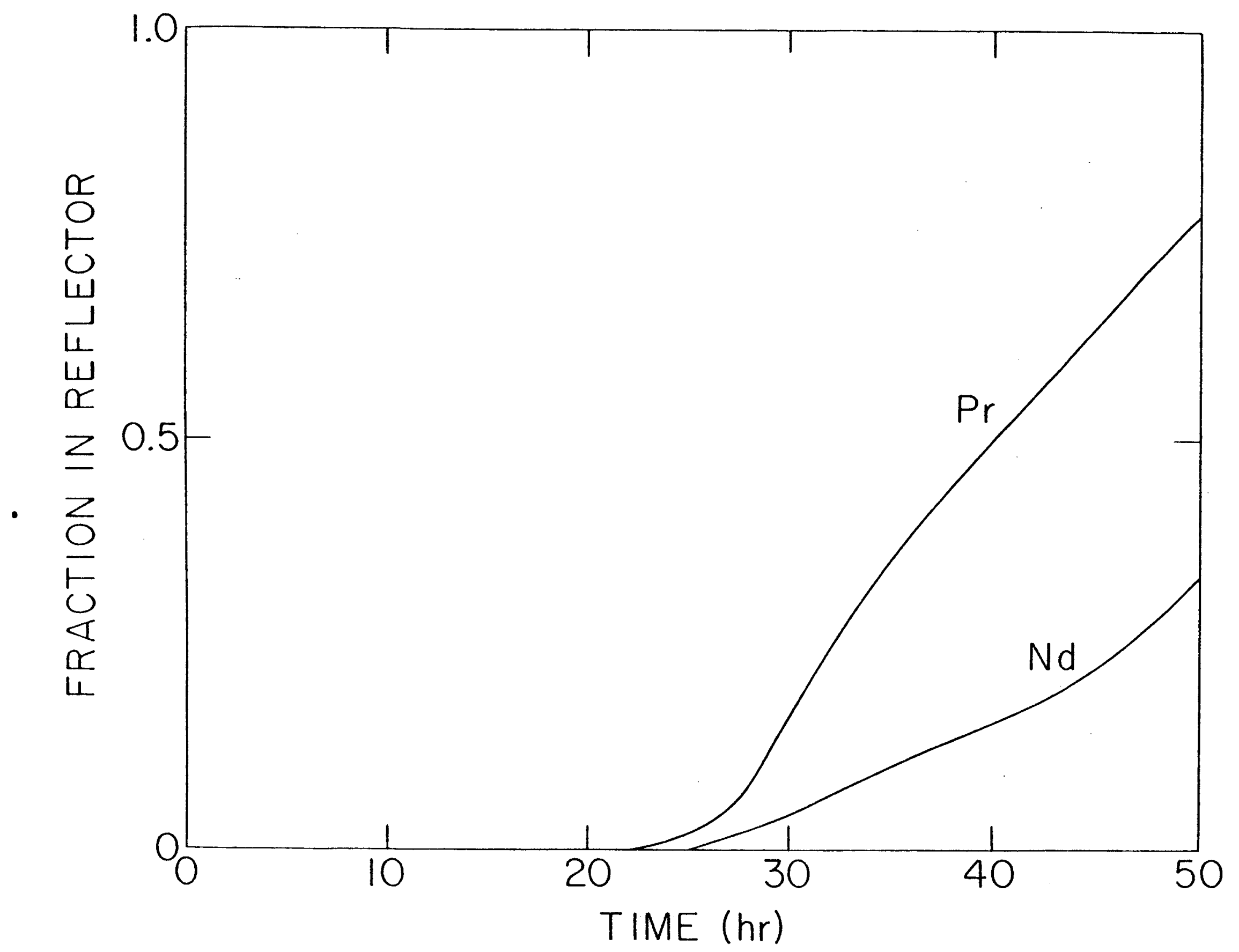

Figure 5.4 


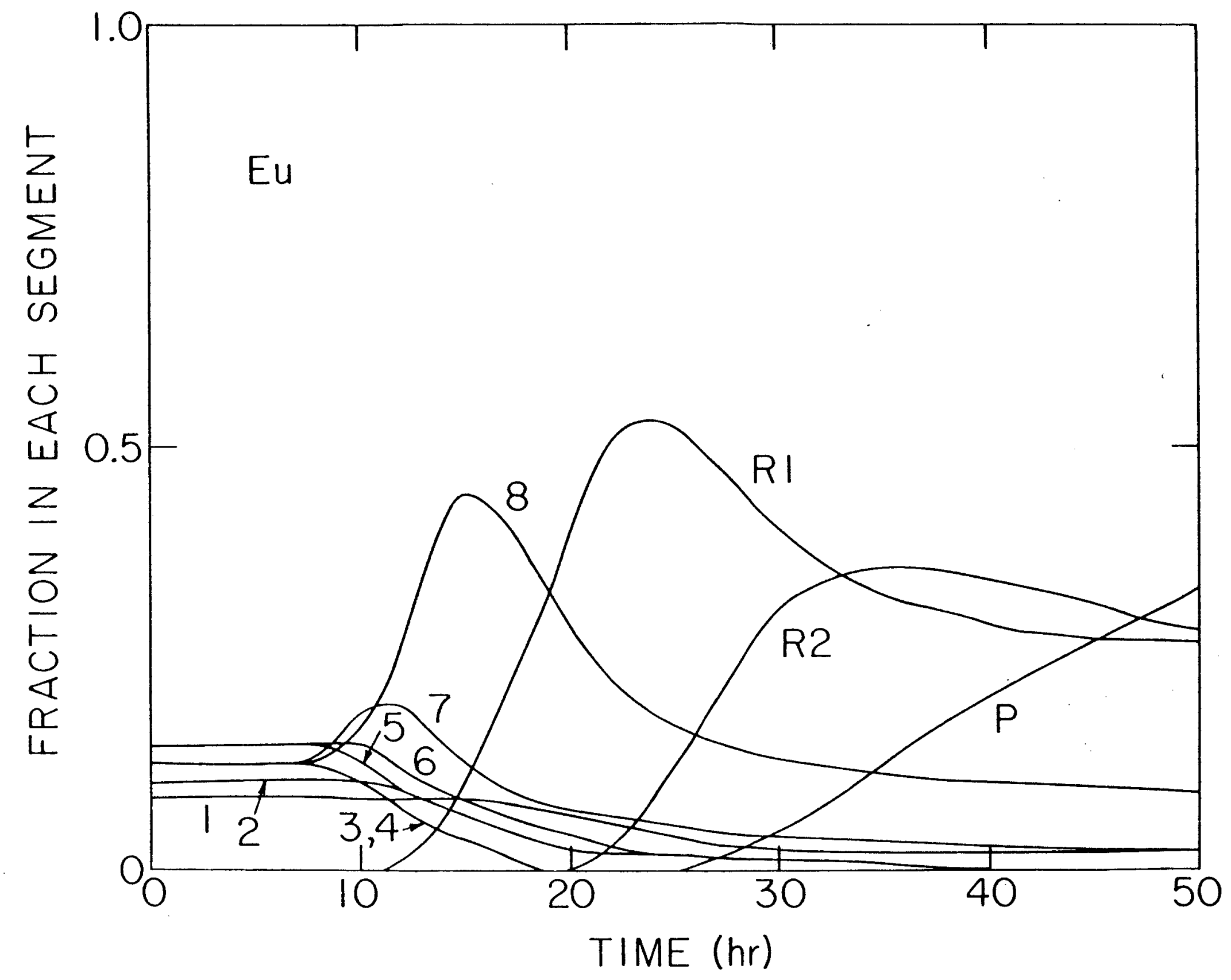

Figure 5.5 


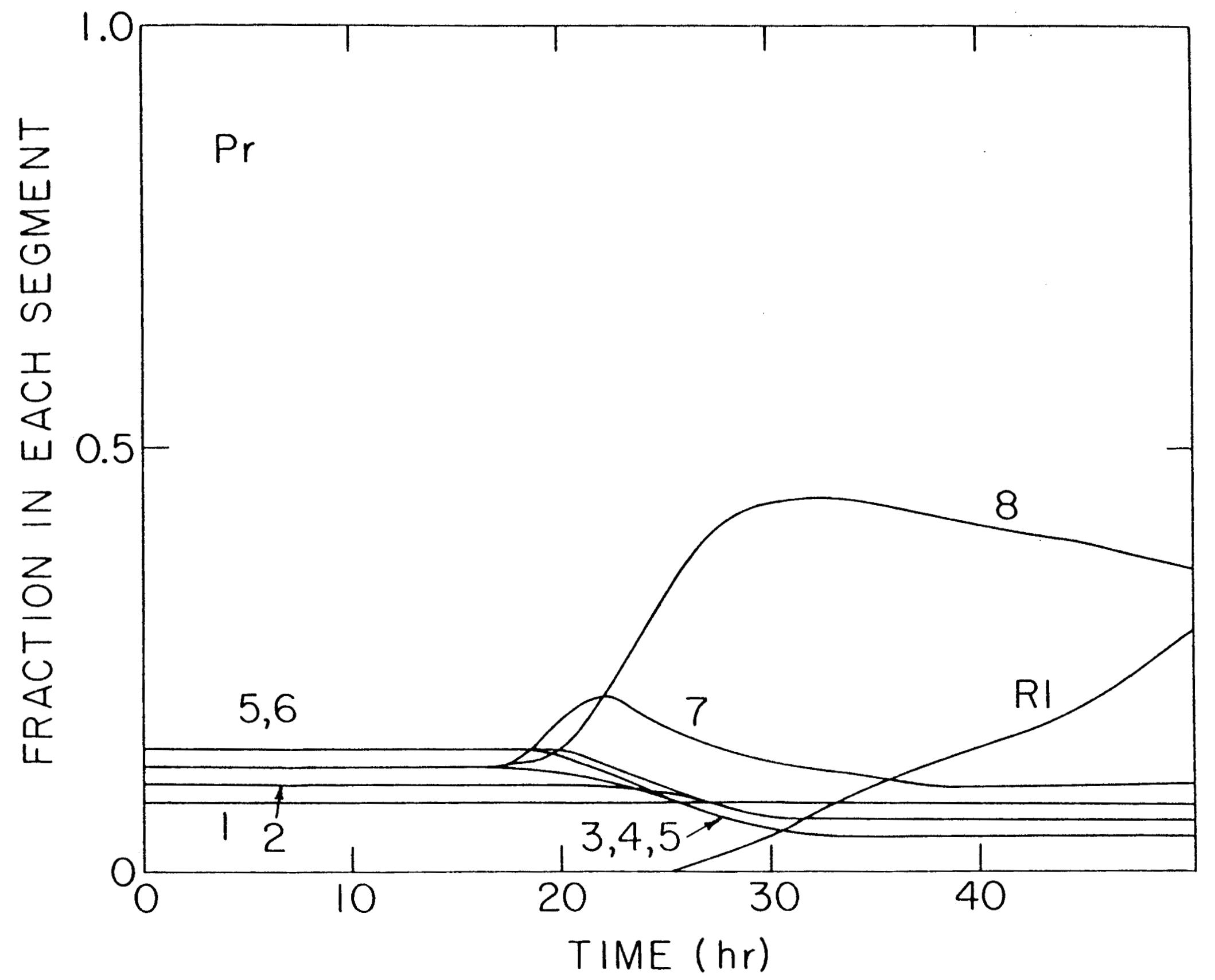

Figure 5.6 


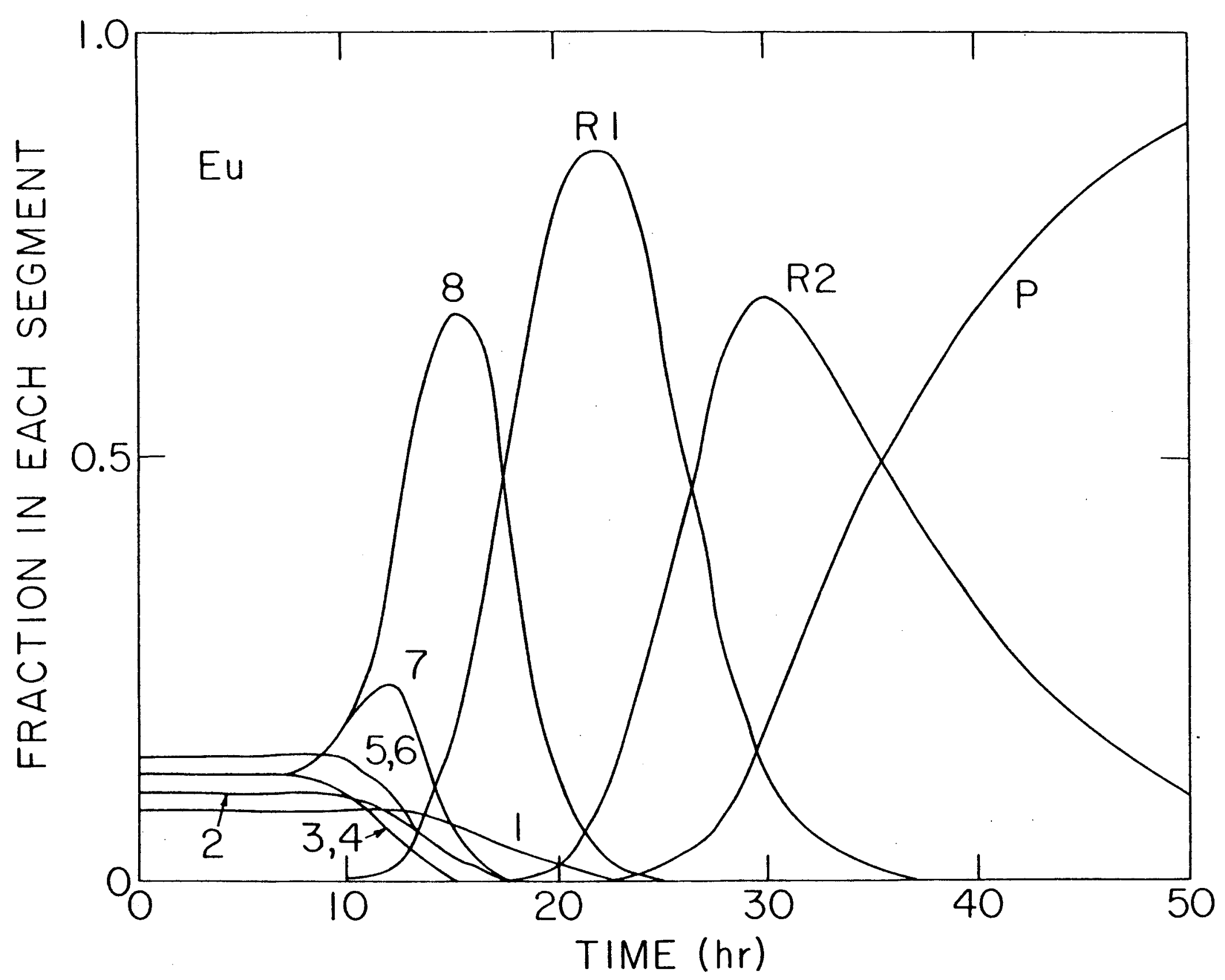

Figure 5.7 


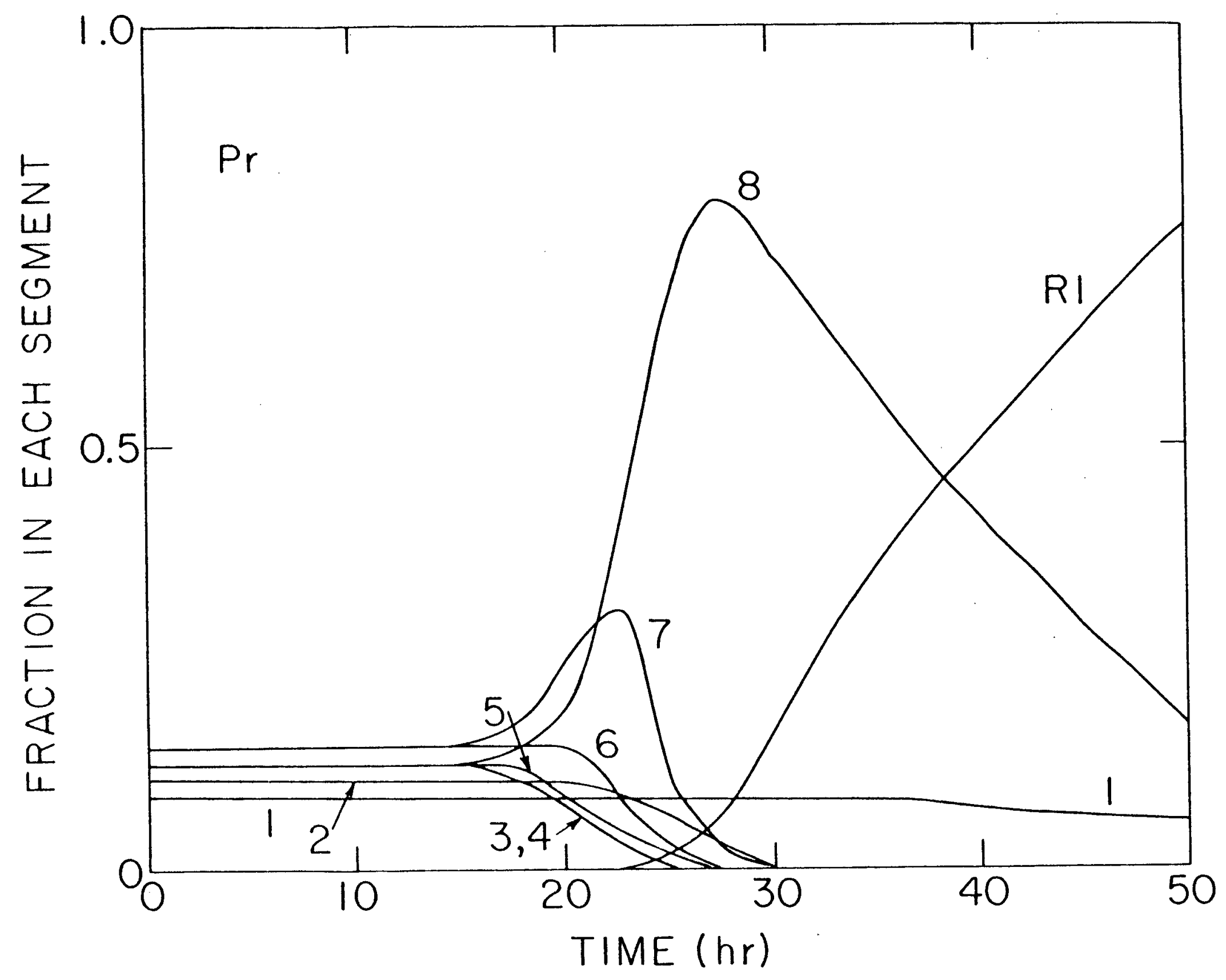

Figure 5.8 


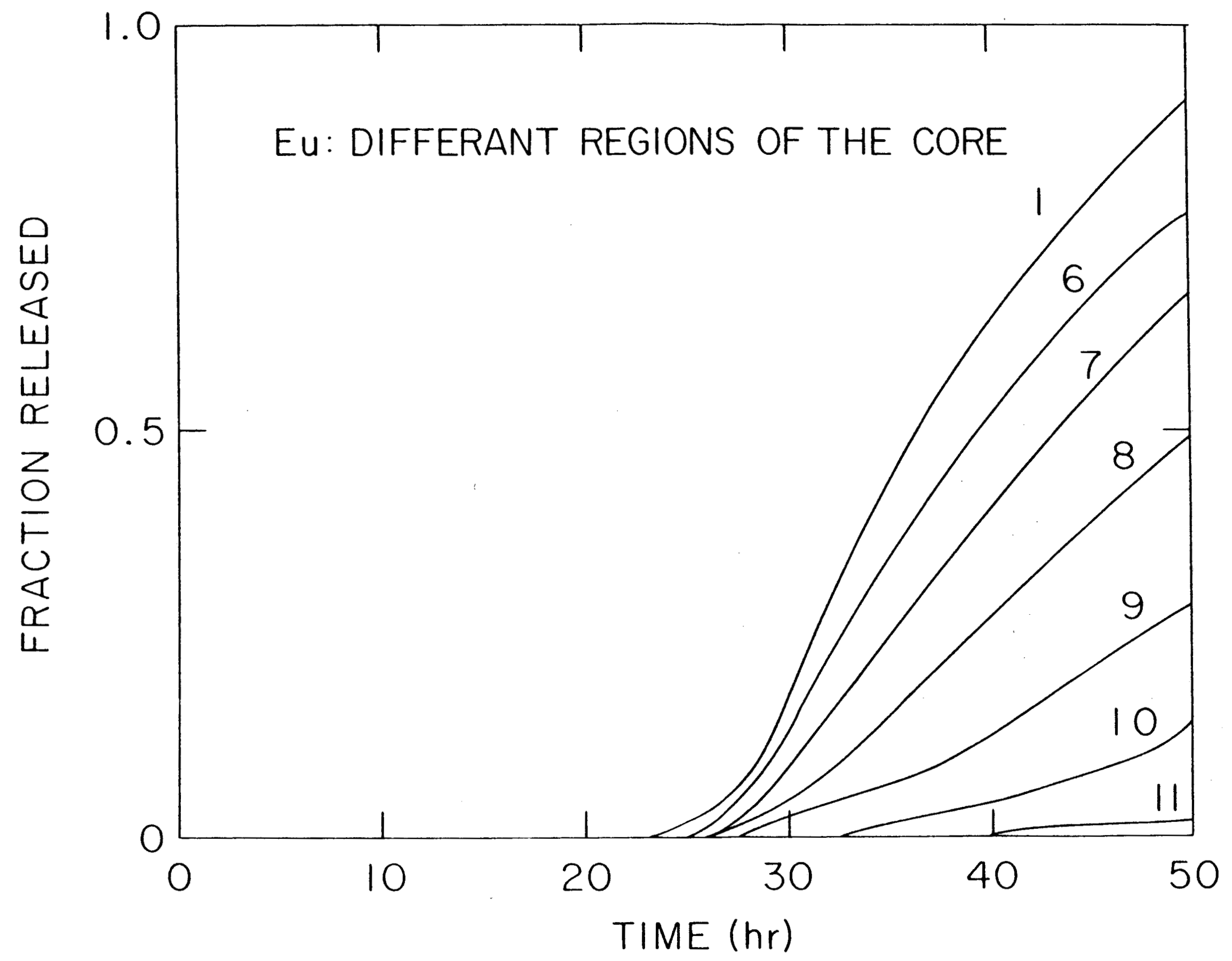

Figure 5.9 


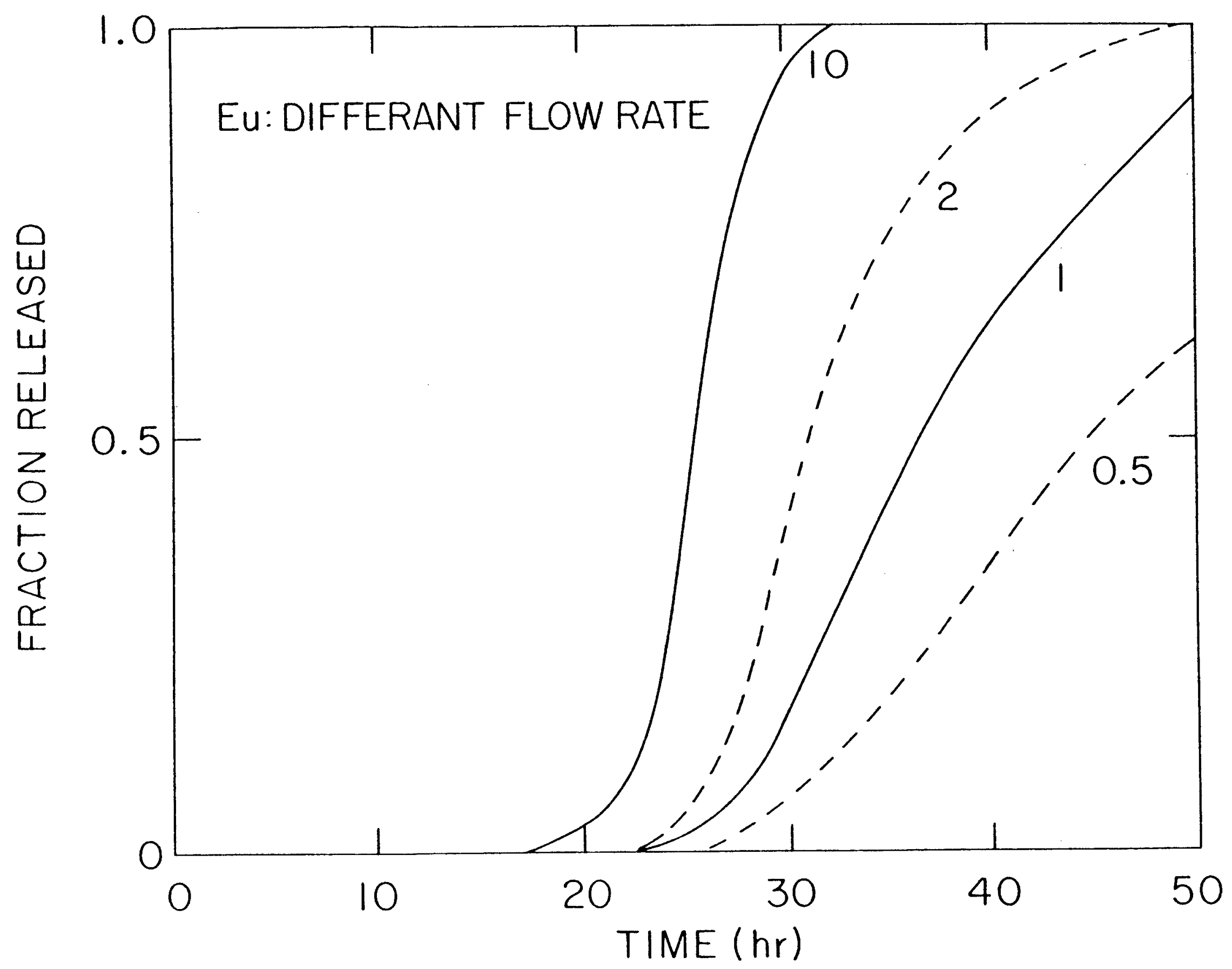

Figure 5.10 


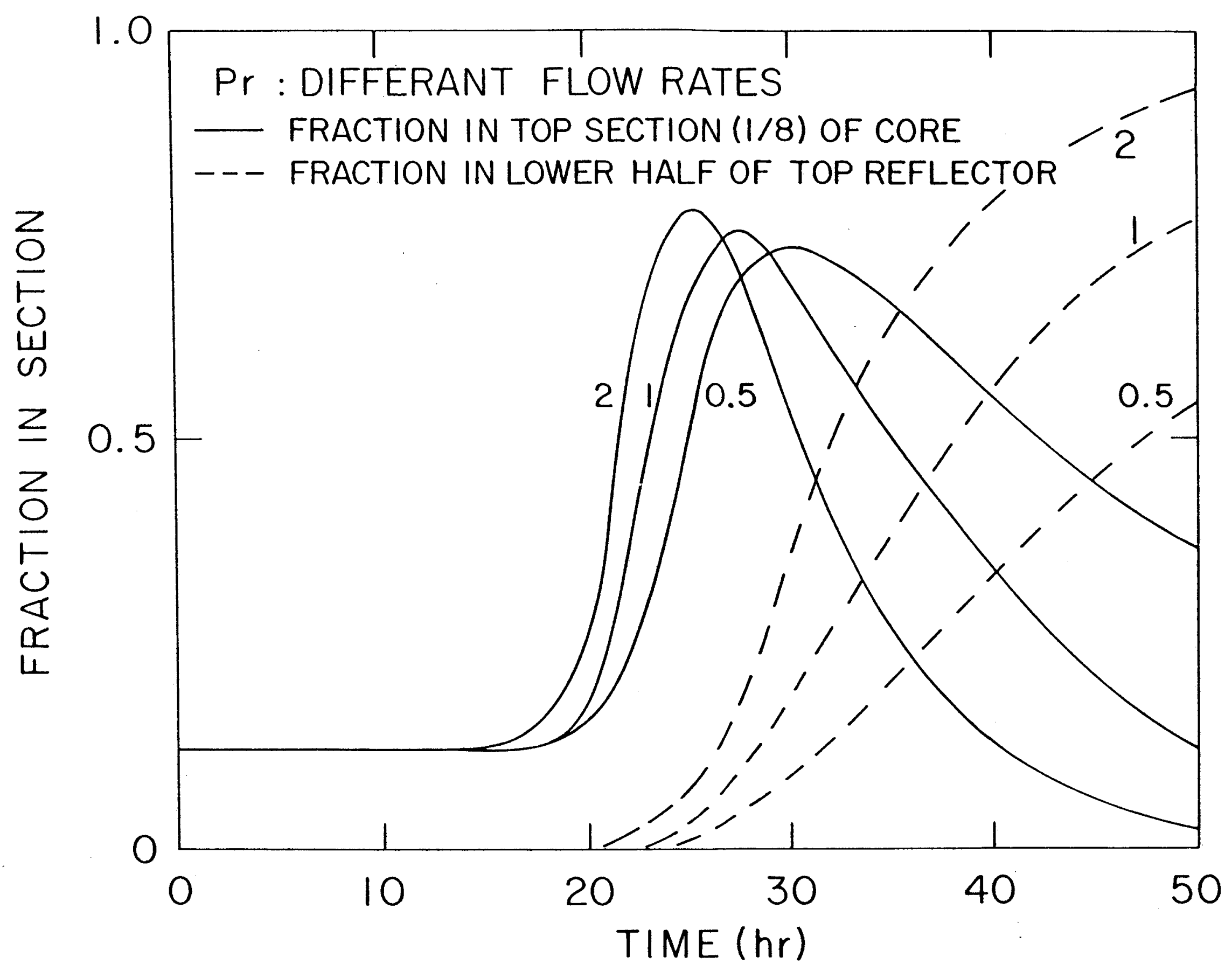

Figure 5.11 


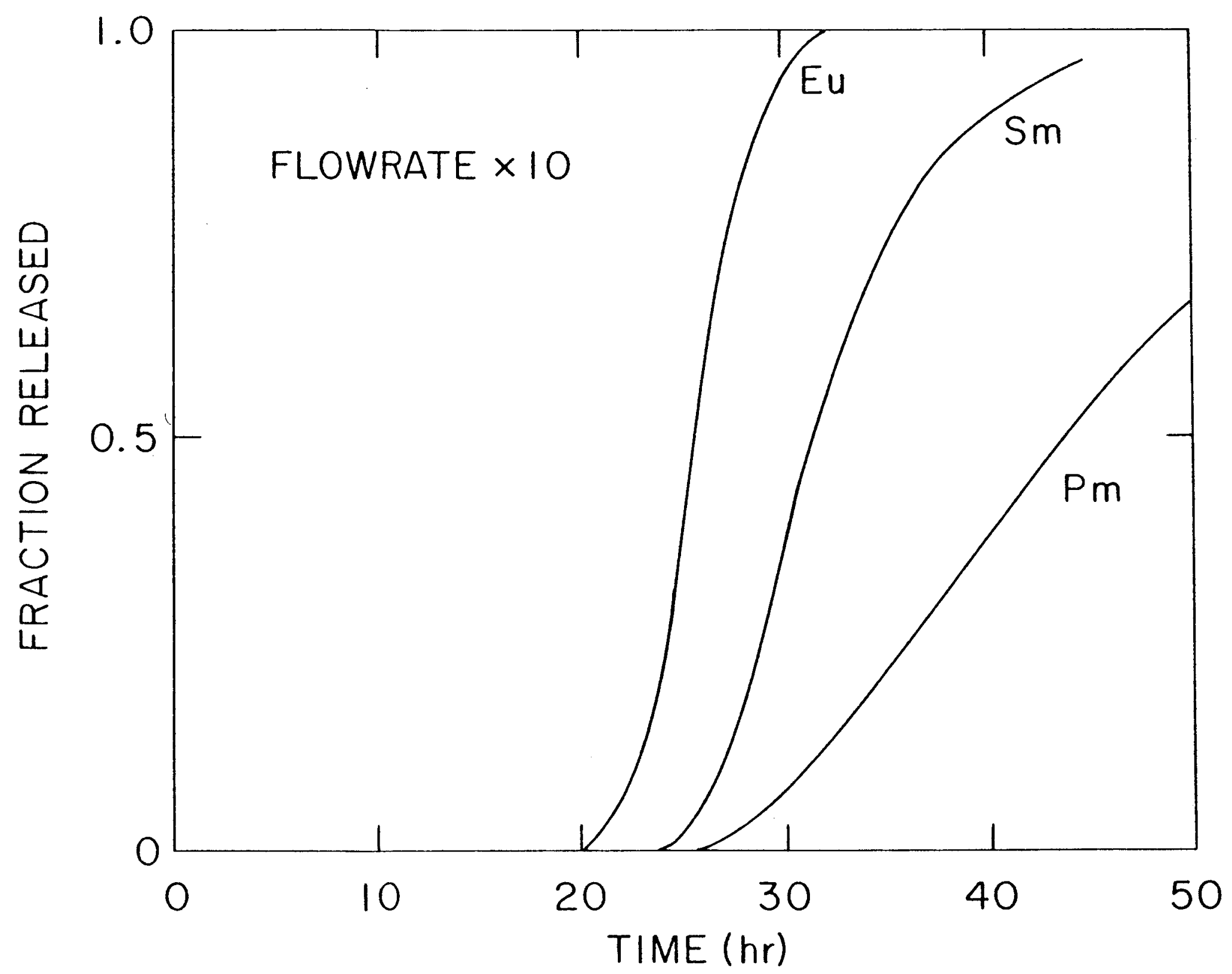

Figure 5.12 


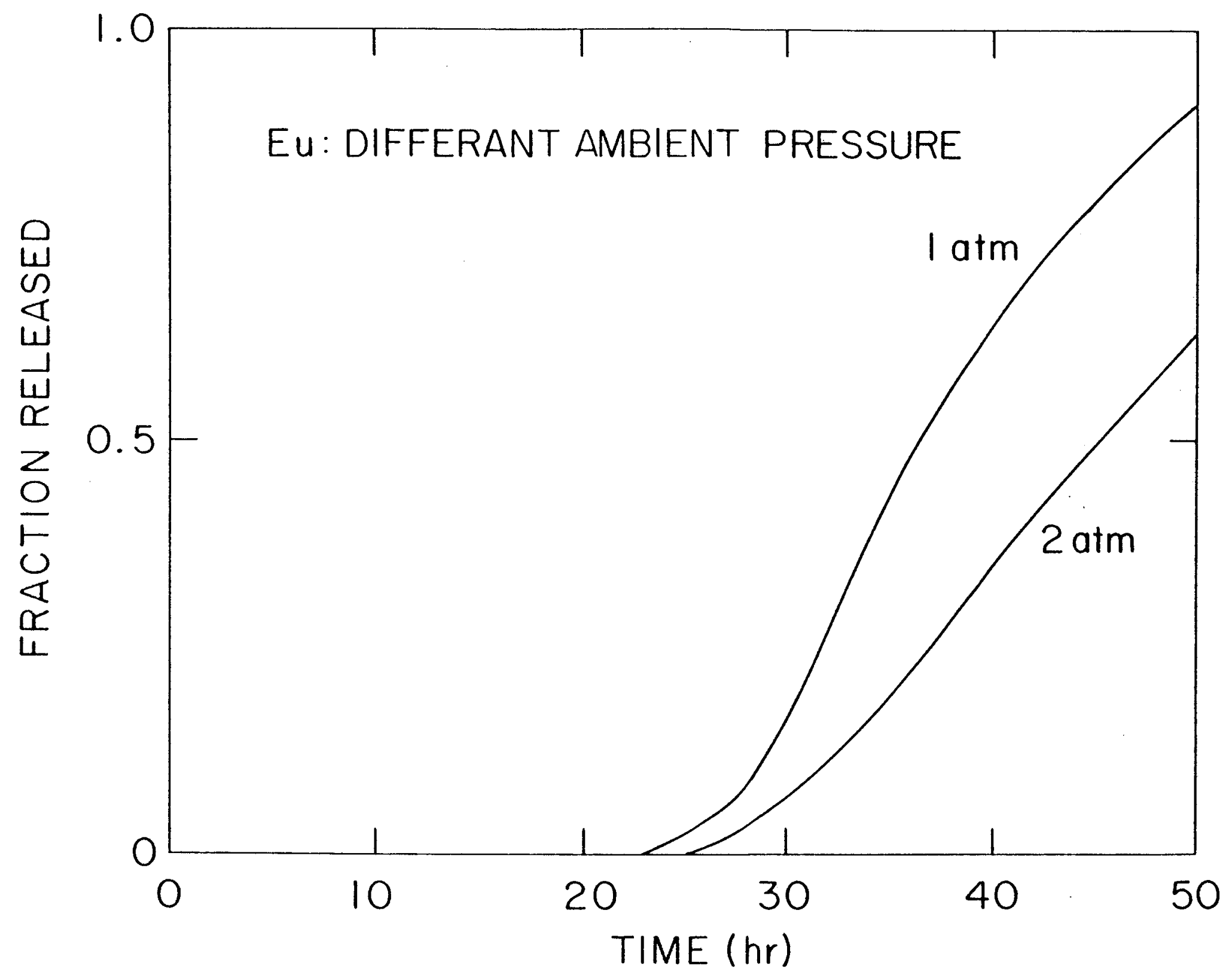

Figure 5.13 


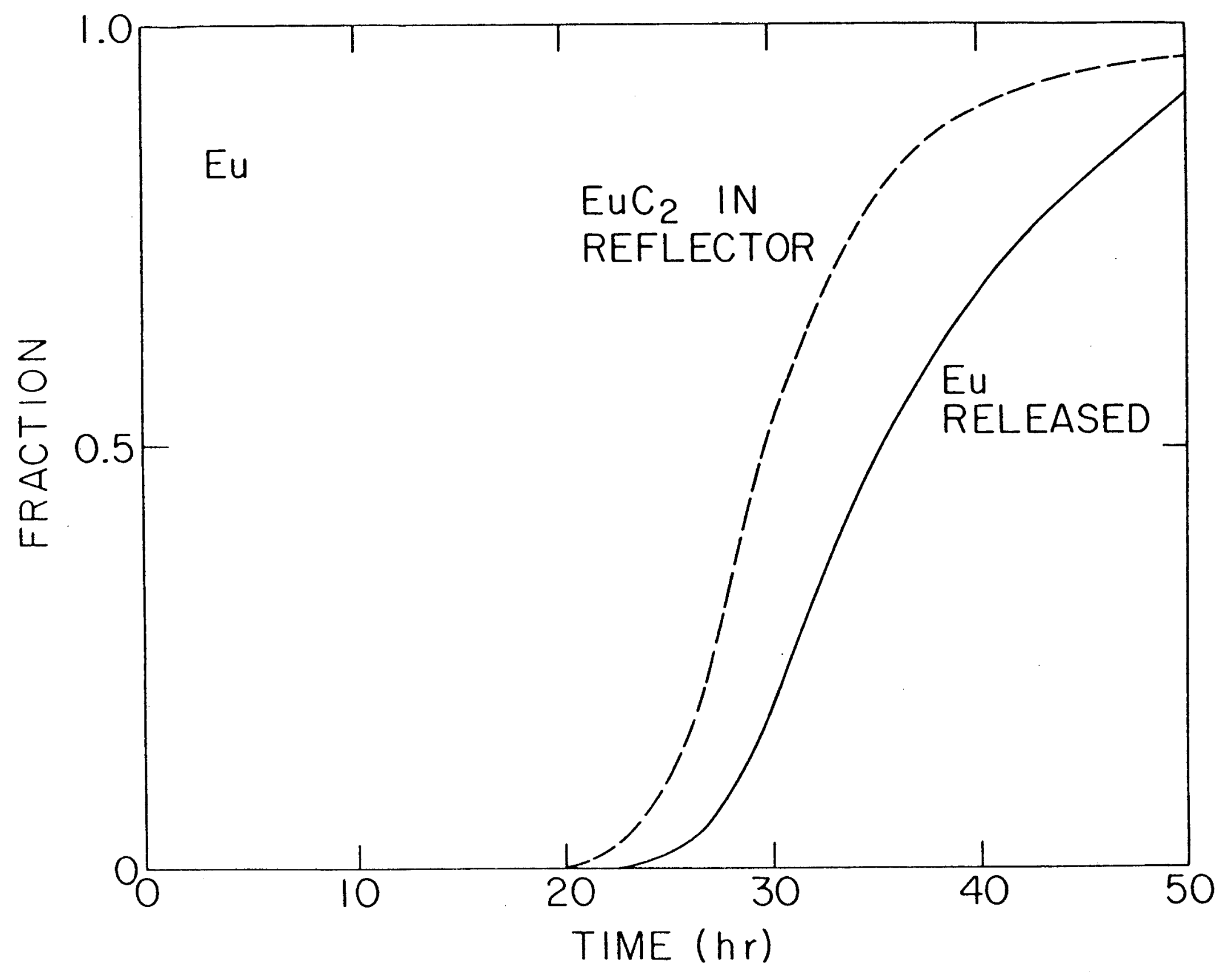

Figure 5.14 


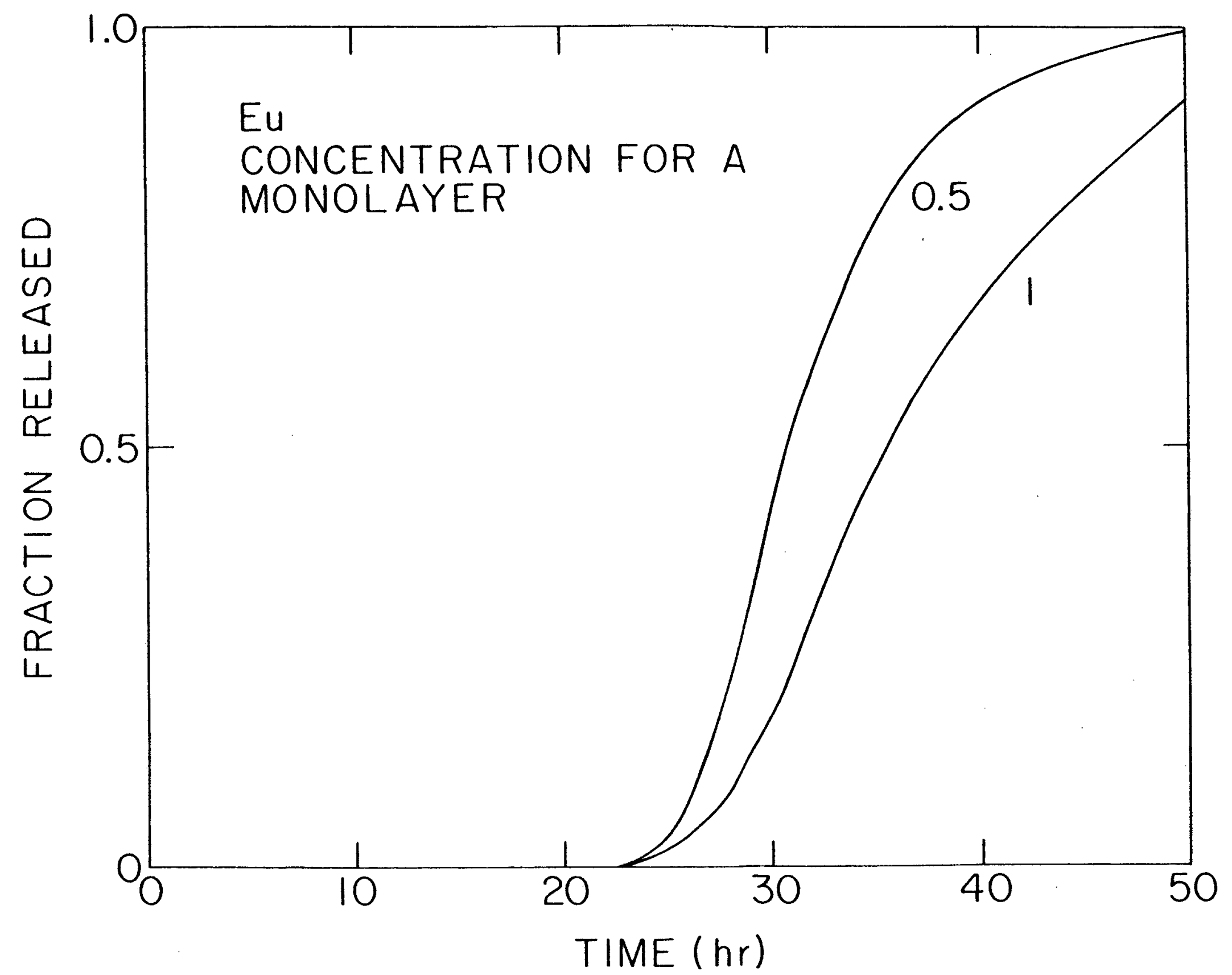

Figure 5.15 


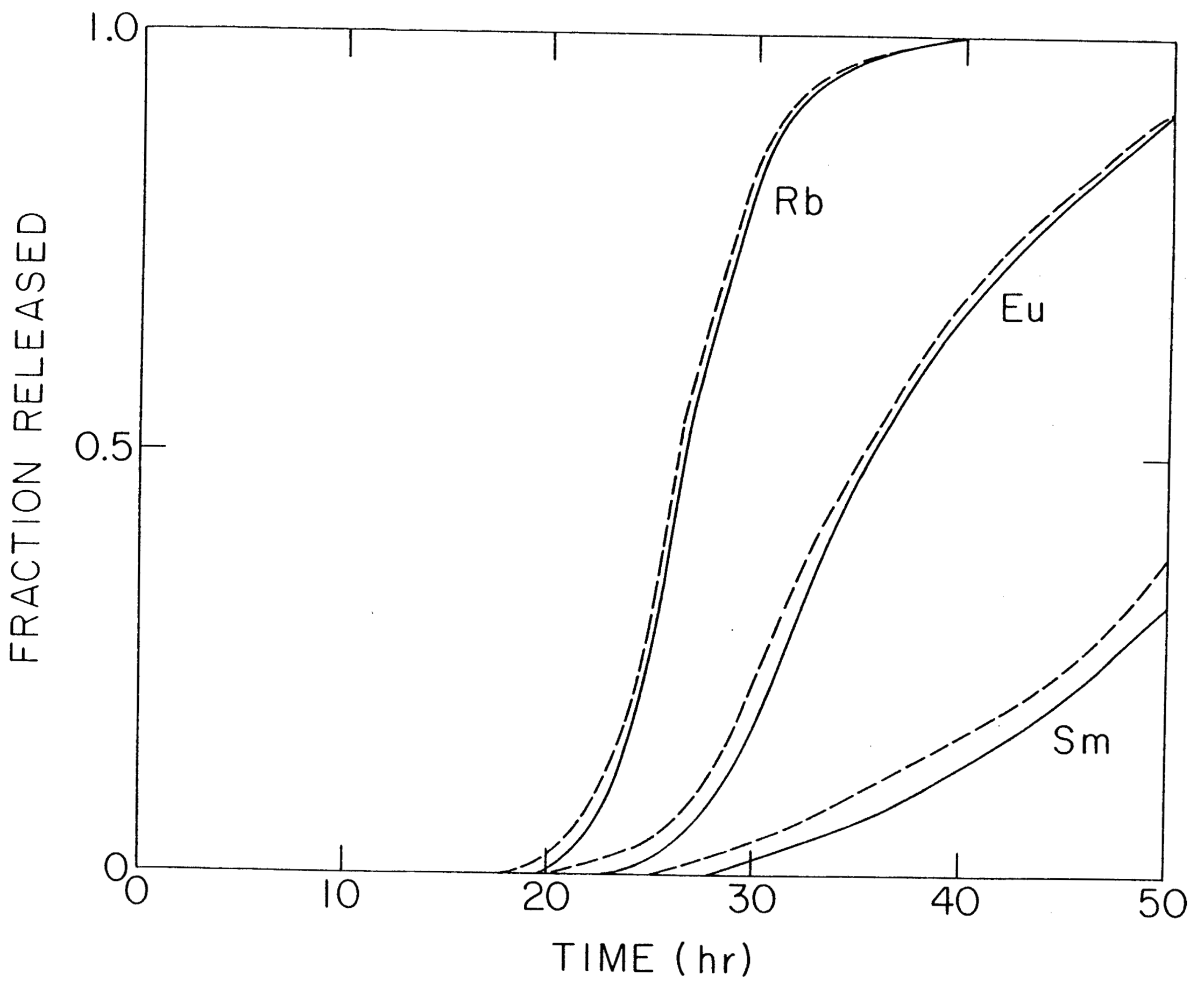

Figure 5.16 